\title{
Functional Dyes, and Some Hi-Tech Applications
}

\author{
Reda M. El-Shishtawy ${ }^{1,2}$ \\ ${ }^{1}$ Chemistry Department, Faculty of Science, King Abdul-Aziz University, P.O. Box 80203, \\ Jeddah 21589, Saudi Arabia \\ ${ }^{2}$ Textile Research Division, National Research Centre, El-Behouth Street, \\ Dokki, Cairo 12622, Egypt
}

Correspondence should be addressed to Reda M. El-Shishtawy, elshishtawy@hotmail.com

Received 14 May 2009; Accepted 2 September 2009

Recommended by Ugo Mazzucato

An overview of the recent developments in functional dyes, which are useful for hi-tech applications for those based on optoelectronics, such as dye sensitized solar cells, photochromic dyes and biomedical applications, such as photodynamic therapy for the treatment of cancer and fluorescent sensors is presented.

Copyright (C 2009 Reda M. El-Shishtawy. This is an open access article distributed under the Creative Commons Attribution License, which permits unrestricted use, distribution, and reproduction in any medium, provided the original work is properly cited.

\section{Introduction}

Functional dye term appeared for the first time in 1981 by Japanese scholars [1]. This new term has come out of renewed interest and activity in the field of dye chemistry closely related with high-technology (hi-tech) applications different from the well-know traditional applications.

Hi-tech applications based on optoelectronics, such as dye sensitized solar cells, photochromic materials, liquid crystal displays, and the newer emissive displays such as organic light emitting devices; electronic materials, such as organic semiconductors; imaging technologies, such as electrophotography (photocopying and laser printing), thermal printing, and especially ink-jet printing; "invisible" imaging by using infrared absorbers in optical data storage, computer-to-plate and security printing; biotechnology as dye-affinity chromatography for the purification of proteins and enzymes; biomedical applications, such as fluorescent sensors and anticancer treatments such as photodynamic therapy, created the need for novel dyes to meet new and demanding criteria.

Dyes, and related ultraviolet and particularly infrared active molecules, which have been specifically designed for these hi-tech applications, are generally called functional dyes.

\section{Aim of the Article}

The present state of the art article attempts to provide an overview of the recent developments in functional dyes. Emphasis will be paid to the recent design of dye molecules, which are useful for hi-tech applications for those based on optoelectronics, such as dye-sensitized solar cells (DSCs), photochromic dyes, and biomedical applications, such as photodynamic therapy (PDT) for the treatment of cancer and fluorescent sensors.

\section{Optoelectronic Applications}

3.1. Solar Cells. The forecasts for the next 50 years predict that human energy needs are likely to double while fossil energy reserves are shrinking. At the same time, on earth, per year, plants and bacteria capture and convert light into a quantity of biological material greater than 100 times the food needed for mankind [2].

The natural light harvesting systems of plants and photosynthetic bacteria are one of the most fascinating functional molecular assemblies, which inspired many scientists for mimicking such process to harvest the solar energy. The first requirement for a light-harvesting system is, of course, its capacity to absorb light. If the system has to be used for 


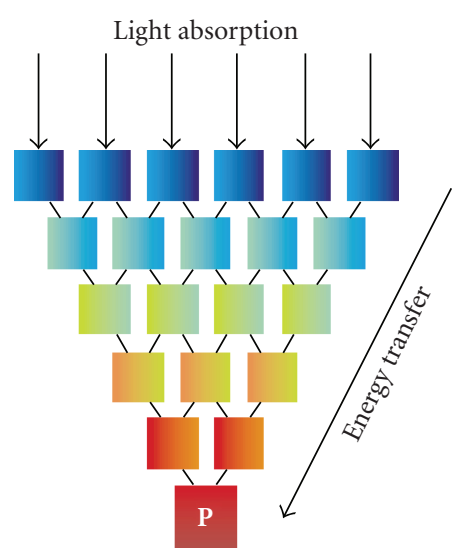

FIGURE 1: Schematic representation of an artificial antenna for light harvesting. Absorption of light by an array of chromophores is followed by vectorial energy transfer that leads excitation energy to a reaction center indicated by $\mathbf{P}$.

artificial solar energy conversion, the absorption spectrum of its components should cover a substantial part of the visible spectral region. Another essential property of the light-absorbing units of an antenna system is their chemical and photochemical stability. As schematized in Figure 1, in an antenna system the excitation energy must be delivered to a common acceptor component. This implies the occurrence of a sequence of energy transfer steps along predetermined directions [3-6].

The conversion of sunlight into electricity is a clean, abundant, and renewable energy source. The efficiency of conventional solar cells, or photovoltaic devices, made from inorganic materials reached up to $24 \%$ [7], using very expensive materials of high purity and energy intensive processing techniques.

New ways of manufacturing solar cells that can scale up to large volumes and low cost are required. In this interest a new generation of solar cells called dye-sensitized solar cells (DSCs) has been reported in 1991 by O'Regan and Grätzel [8]. In contrast to conventional systems, in which the semiconductor assumes both the task of light absorption and charge carrier transport, the two functions are separated in DSCs [9].

A dye-sensitized solar cell of Grätzel type $[8,10$, 11] shown Figure 2 typically consists of a dye-adsorbed nanoporous $\mathrm{TiO}_{2}$ film prepared on transparent conductive oxide, such as conductive glass. The film is immersed in an electrolyte containing a redox couple and placed on a platinum counter electrode. After absorption of a photon, the excited electron within the sensitizer molecule is transferred to the conduction band of $\mathrm{TiO}_{2}$ and diffuses through the porous $\mathrm{TiO}_{2}$ network to the contact. The oxidized sensitizer molecule is reduced to the original state by supply of electrons through a liquid electrolyte redox couple within the pores.

3.1.1. Mechanism of DSC. Light absorption is performed by a monolayer of dye (D) adsorbed chemically at the semiconductor surface and excited by a photon of light (1). After having been excited $\left(D^{*}\right)$ by a photon of light, the dye-usually a transition metal complex whose molecular properties are specifically for the task-is able to transfer an electron to the semiconductor $\left(\mathrm{TiO}_{2}\right)$ by the injection process (2). The efficiency of a DSC in the process for energy conversion depends on the relative energy levels and the kinetics of electron transfer processes at the liquid junction of the sensitized semiconductor/electrolyte interface.

For efficient operation of the cell, the rate of electron injection must be faster than the decay of the dye-excited state. Also, the rate of reduction of the oxidized sensitizer (dye cation) by the electron donor in the electrolyte (4) must be higher than the rate of back reaction of the injected electrons with the dye cation (3), as well as the rate of reaction of injected electrons with the electron acceptor in the electrolyte (5) [12]:

$$
\begin{gathered}
\mathrm{TiO}_{2} / \mathrm{D}+h v \longrightarrow \mathrm{TiO}_{2} / \mathrm{D}^{*} \\
\mathrm{TiO}_{2} / \mathrm{D}^{*} \longrightarrow \mathrm{TiO}_{2} / \mathrm{D}^{+}+\mathrm{e}_{\mathrm{cb}} \\
\mathrm{TiO}_{2} / \mathrm{D}^{+}+\mathrm{e}_{\mathrm{cb}} \longrightarrow \mathrm{TiO}_{2} / \mathrm{D} \\
\mathrm{TiO}_{2} / \mathrm{D}^{+}+(3 / 2) \mathrm{I}^{-} \longrightarrow \mathrm{TiO}_{2} / \mathrm{D}+(1 / 2) \mathrm{I}_{3}^{-} \\
(1 / 2) \mathrm{I}_{3}^{-}+\mathrm{e}_{(\mathrm{pt})} \longrightarrow(3 / 2) \mathrm{I}^{-}, \mathrm{I}_{3}^{-}+2 \mathrm{e}_{\mathrm{cb}} \longrightarrow 3 \mathrm{I}_{3}^{-}
\end{gathered}
$$

3.1.2. Structure Design of Sensitizers. Dye sensitizers serve as the solar energy absorber in DSC, whose proprieties will have much effect on the light harvesting efficiency and the overall photoelectric conversion efficiency. The ideal sensitizer for DSCs should absorb all light below a threshold wavelength of about $920 \mathrm{~nm}$. In addition, it should be firmly grafted to the semiconductor oxide surface and inject electrons to the conduction band with a quantum yield of unity. Its redox potential should be sufficiently high that it can be regenerated rapidly via electron donation from the electrolyte or a hole conductor. Finally, it should be stable enough to sustain at least $10^{8}$ redox turnovers under illumination corresponding to about 20 years of exposure to natural light [13].

The sensitizers used in DSC were divided into two types: organic and inorganic dyes according to the structure. Inorganic dyes include metal complex, such as polypyridyl complexes of ruthenium and osmium, metal porphyrin, phthalocyanine, and inorganic quantum dots, while organic dye includes natural and synthetic organic dyes. To date, DSCs with Ru bipyridyl complexes (N3 and N719) and the black ruthenium dye (Figure 3 ) as photosensitizers have achieved power conversion efficiencies up to $11.2 \%$ and $10.4 \%$, respectively $[14,15]$, compared to just $1 \%$ ten years ago [16].

However, the noble metal $\mathrm{Ru}$ is a limited resource and is expensive. In order to obtain even cheaper photosensitizer for DSCs, metal-free organic photosensitizers are strongly desired. Metal-free organic dyes offer superior molar extinction coefficients, low cost, and a diversity of molecular structures. Recently, novel photosensitizers such as coumarin 



Figure 2: Grätzel type DSC.



N3

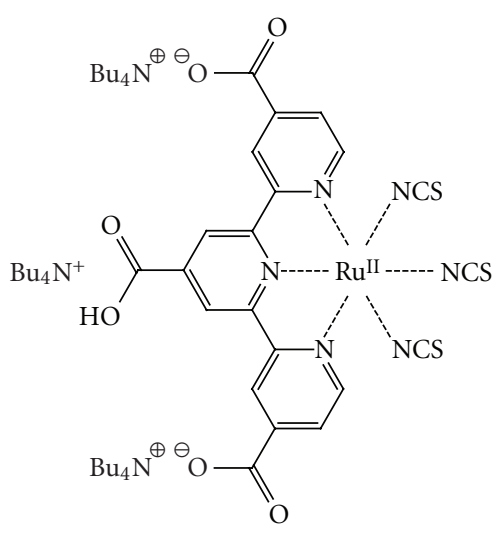

Black dye



N719

Figure 3: Chemical structure of N3, N719, and the black ruthenium dye.

[17], merocyanine [18], cyanine [19], indoline [20], hemicyanine [21], triphenylamine [22-25], dialkylaniline [26], bis(dimethylfluorenyl) aminophenyl [27, 28], phenothiazine [29], tetrahydroquinoline [30], and carbazole [31] based dyes have achieved solar-to-electrical power conversion efficiencies up to $5 \%-9 \%$.

For a higher photovoltage and higher conversion efficiency, the charge recombination process at the interface should be retarded [32-35]. The recombination of the injected conduction-band electrons with the oxidized dye molecules and the redox species in the electrolyte are two possible recombination pathways. It has been confirmed that the charge recombination process can be retarded by a larger physical separation of the dye cation state from the surface of nanocrystallite film $[36,37]$.

An efficient dye is usually designed to be of donorconjugated bridge-acceptor structure called donor-acceptor architecture. Most dye molecules have only one donor group $[17,27-30]$, and interest is growing to design dyes containing two electron-donating groups $[24,25,38-42]$, as shown in
Figure 4. The presence of two electron donating groups in the dye molecule would lead to lowering the LUMO energy level and thus enhance the rate of electron injection from the excited dye molecules to the conduction band of the $\mathrm{TiO}_{2}$ film when compared with only one donating group (plus other advantages, see below).

The structural design of the dyes $1-8$ is shown in Figure 4. The dye molecules are composed of three parts: (1) one or two donating groups to enhance the electrondonating ability and effectively inhibit $\mathrm{I}_{3}^{-}$from approaching the surface of nanocrystallite $\mathrm{TiO}_{2}$ film by the formation of a denser dye layer at the surface of the $\mathrm{TiO}_{2}$ film, (2) an oligothiophene or conjugated bridge or polyene to tune the absorption spectra of the dye molecules by changing the length of conjugation, and (3) a cyanoacrylic acid to act as the acceptor and the anchoring group to fix the dye onto the surface of semiconductor film electrode.

Light stability of organic dye sensitizers is another factor to be considered in the structural design of the dye molecules, since the main disadvantage of organic dye sensitizers in 



4

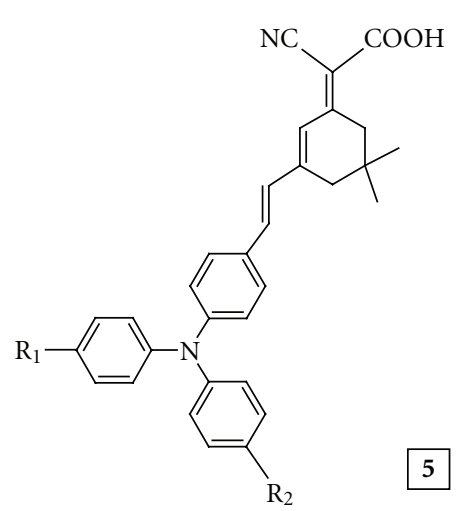<smiles>[R]N([R])c1ccc(C(=CC=CC=C(N)C(=O)O)c2ccc(N([R])[Y])cc2)cc1</smiles>



Figure 4: Chemical structure of designed dyes for DSCs. 
comparison with inorganic ones is their stability, which is generally lower than that of metal complexes, because of side reactions such as formation of excited triplet states and unstable radicals. In this interest, the design features indicated in dye 3 have shown high light stability [40].

It has been reported that dye aggregation on the semiconductor surface is the main factor in decreasing the efficiency of sensitized photocurrent generation [43]. Therefore, one has to consider this factor in the structural design of the dye. This design is implemented in dyes $1-8$ as they contain diphenylaniline or diarylaniline moiety which is nonplanar and would suppress aggregation due to the disturbance of the $\pi-\pi$ stacking $[44,45]$. Introducing bulky groups in the chromogen of the dye would decrease dye aggregation; for example, 3,5-di-tert-butylphenyl groups were introduced at the meso positions of the porphyrin ring as shown in Figure 5 [46].

Unlike artificial dyes, the natural ones are available, easy to prepare, low in cost, nontoxic, and environmentally and fully biodegradable. In this interest the use of anthocyanins such as cyanin dye (Figure 6) for DScs has been reported $[47,48]$.

The structure of the dye has the design needed for DSCs as it has two othro hydroxyl groups as donors in conjugation with oxonium moiety. This feature would lead to the formation of orthoquinoide form upon anchoring onto $\mathrm{TiO}_{2}$ nanoparticles (Figure 7). However, much work is needed to enhance the efficiency of solar energy conversion for this kind of natural dyes.

\subsection{Photochromic Dyes}

3.2.1. Mechanism of Photochromism. Photochromism refers to a reversible phototransformation of a chemical species between two forms having different absorption spectra [49]. Thus, photochromic molecules can be regarded as photochromic switches as they can exist in two forms of different spectral properties.

An important class of organic photochromes at the present time is the spiropyrans and the closely related spirooxazines. As shown in Figure 8, UV irradiation of the colorless photochromic results in the electrocyclic ring opening of the pyran or oxazine moiety via the cleavage of the $\mathrm{C}(\mathrm{sp} 3)-\mathrm{O}$ bond. This produces a distribution of isomeric open forms (merocyanines) that are intensely colored because of their extended conjugation and quasiplanar conformations.

Another promising family of photochromic compounds is provided by the synthetic flavylium salts, benzopyrylium derivatives, which have the same basic structure as anthocyanins mentioned above. Photochromism based on flavylium systems arises from the photoinduced trans-cis isomerization reaction that produces cis form, which undergoes ring closure to form the flavylium form (Figure 9). The structural feature of this type photochromes reveals that they are $\mathrm{pH}$ sensitive and their photochromisms are affected by the medium in which they are used. Therefore, flavylium photochromes are considered as good probes for assessing

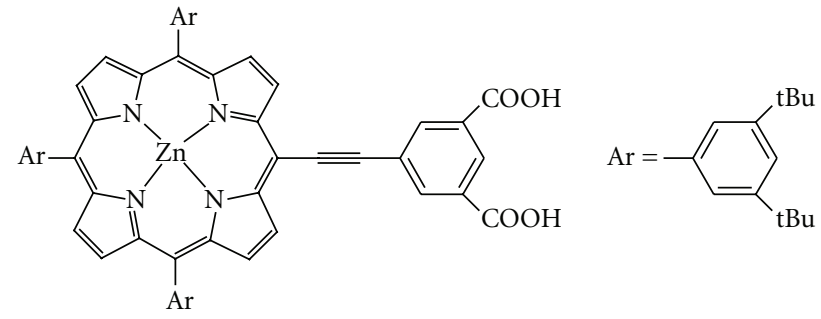

Figure 5<smiles></smiles>

Figure 6: Chemical structures of cyanin dye.<smiles></smiles>

Figure 7: Schematic representation of anchoring cyanin dye (quinonodial form) onto $\mathrm{TiO}_{2}$ layer.

changes in the polymer microenvironment, such micelles and gels [50].

3.2.2. Structure Design of Photochromic Dyes. Recent progress in information technologies toward increasing capacity of 


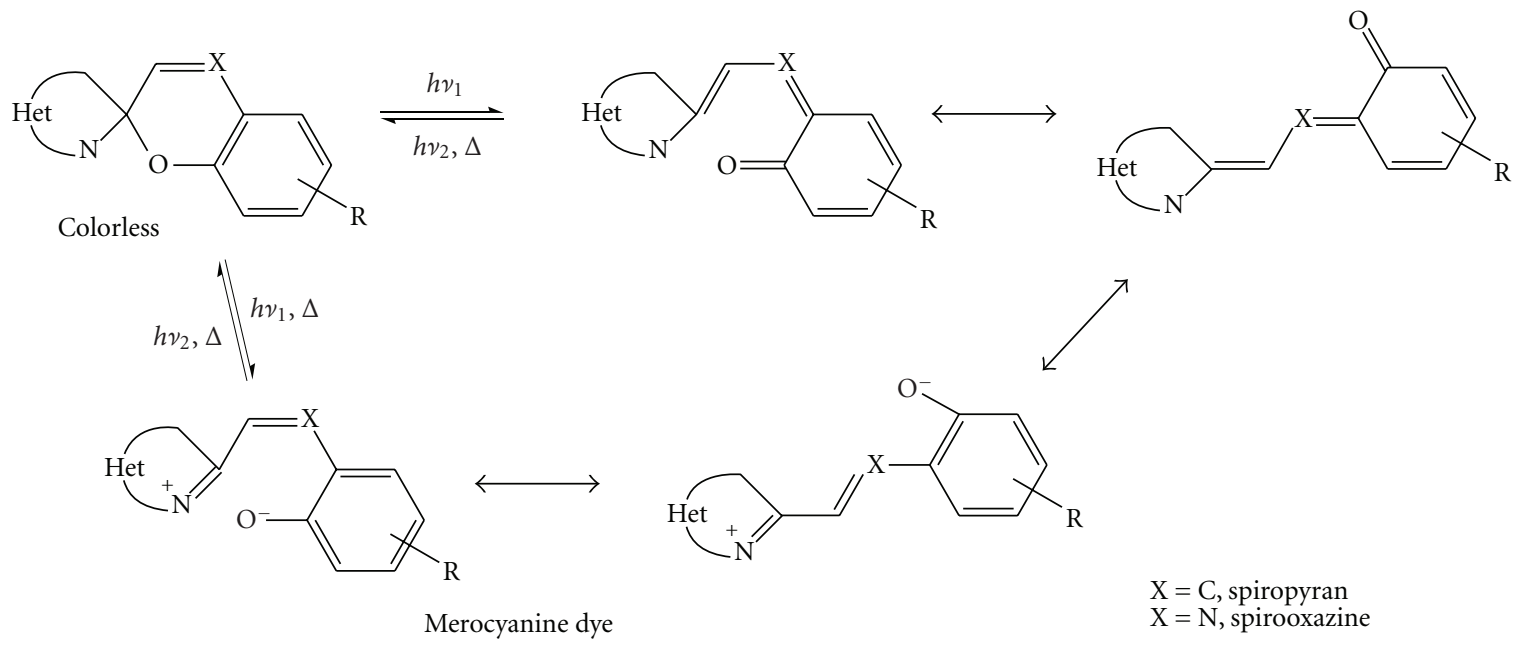

FIGURE 8: Photochromism mechanism of a typical spiropyran or spirooxazine.

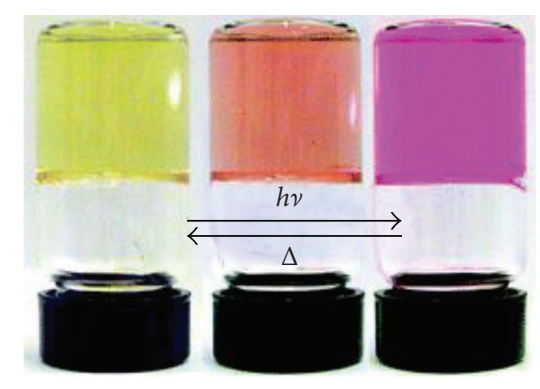<smiles>CCNc1ccc(/C=C/C(=O)c2ccc(O)cc2)c(O)c1</smiles>

FIGURE 9: Highly transparent photochromic gels in the visible region can be prepared by the incorporation of flavylium compounds in Pluronic matrixes (ABA-type tri-block copolymers composed of poly(ethylene oxide) (PEO) (A) and poly(propylene oxide) (PPO) units (B)). The chromophore 7-(N,N-diethylamino) 4-hydroxyflavylium switches from its yellow chalcone form to the red flavylium cation upon irradiation and reverts back to the chalcone form in the dark.

optical information carriers and information processing rates makes urgent the development of new lightsensitive media for use in super high-capacity optical memory. Compared to the thermal principle of data recording on modern optical disks, the photochemical principle of optical data recording on photochromic multilayer optical disks can be expected to ensure a higher density of data recorded on the pico- or femtosecond scale.

Therefore, photonic devices that incorporate photochromic molecules represent the future of digital optical storage where the recording of information is an all photomode recording method that allows the read, write, and erase functions to be controlled by light energy [49, 5157]. In photomode recording, light characteristics such as wavelength, polarization, and phase can be multiplexed to enable data storage and potentially increases the memory density [58-63].

One promising approach is the development of photochromic materials. These materials can interconvert between two distinct isomeric states when stimulated by two different wavelengths of light, where each isomer of the photochromic materials can represent " 0 " and " 1 " of a digital mode. Molecules with this behavior are the best promising candidate optical storage materials as opposed to heatmode recording employed with the optical media currently in use.

The most well-known organic photochromic switches are based on the ring opening/ring closure reactions in photoinduced electrocyclic reactions. There are six main groups of compounds that have found numerous applications as switching molecules: dihydroazulenes and vinylheptafulvenes $[64,65]$, diarylethenes $[55,66]$, spiropyrans [63], spiroxazines $[63,67,68]$, naphthopyrans [69], dihydropyrenes [70], fulgides, fulgimides, and related compounds [71] (Figure 10).

There are many other examples of photoswitchable compounds, but these six classes of compounds are the most widely studied ones. Photoswitching of all of them involves 
<smiles>Cc1ccc(C(=CC2=CC=CC=CC2)C(C#N)C#N)cc1</smiles><smiles></smiles><smiles>Cc1sc2ccccc2c1C1=C(c2ccccc2)C(=O)OC1=O</smiles>
<smiles>Cc1oc(C)c2c(C)c3c(c(C)c12)C(=O)OC3=O</smiles><smiles>[Y]c1ccc(C2=CC3=CC=CC=CC3C2(C)C)cc1</smiles><smiles>N#CC1=C(C#N)C2(c3ccccc3-c3ccccc32)C2C=CC=NN12</smiles>
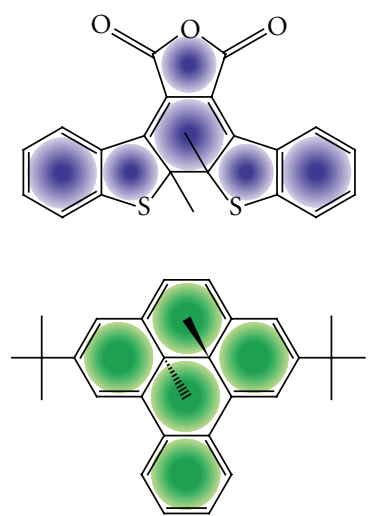<smiles>[R]N1c2ccccc2C2(C)CC1C1c3cc([N+](=O)[O-])ccc3OC12C</smiles><smiles>[Y]N1CC23Oc4ccc5ccccc5c4NC2C3(C)c2ccccc21</smiles><smiles>C1=CC(c2ccccc2)(c2ccccc2)Oc2c1ccc1ccccc21</smiles>

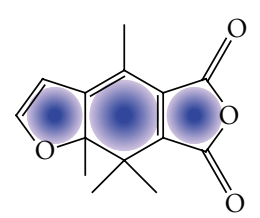

FigURE 10: Structures of opened (left) and closed (right) forms of various representatives of the photochromic switch families. From top to bottom: dihydroazulene, dihydroindolizine, diarylethene, dihydropyrene, spiropyran, spirooxazine, naphthopyran, and fulgide. Colored forms of photochromic compounds are marked with shading. 
reversible formation and opening of rings, and closedring forms of naphthopyrans, spiropyrans, spiroxazines, and fulgides are colorless, while the opened forms are strongly colored; in the case of diarylethenes and vinylheptafulvenes, the opened forms are colorless, and the closed forms are strongly colored. Many molecules have been designed to achieve thermal stability, and they prospectively can be applied in molecular memories as optical storage materials. However, numerous molecules undergo thermal back reactions. This process is disadvantageous from the point of view of long-term information storage, but for shortterm storage and modeling of logic gates, it does not constitute any obstacle [72]. While modifications of the existing photochromes may still generate compounds with unprecedented properties, development of new classes of organic photochromic dyes with novel molecular scaffolds as suitable materials for aforementioned applications remains desired [73-75].

It has been reported that photochromic compounds suitable for photonic applications must meet the following requirements: high cross section for two-photon absorption, high efficiency of photochromic transformations, thermal stability and fatigue resistance to irreversible photo- and thermoinduced transformations of both forms (colorless and colored), and nondestructive readout by any suitable method (via fluorescence, refraction, reflection, polarization, etc.) [76]. Ongoing efforts in this area have focused on increasing the thermal stability of photochromic dyes by mainly two ways, one designing new dye molecules with structural features to fit the necessary criteria mentioned above, and the second is by incorporating the dye molecules in a rigid matrix. It has been reported that organic photochromic compounds which exhibits valent isomerization such as diarylethenes have the above requirements to an utmost extent $[55,77]$. Recently, some new dyes based on diarylenes have been reported $[78,79]$, as represented above in Figure 10.

On the other hand, the inclusion of photochromic molecules such as naphthopyrans in a rigid matrix of $\operatorname{poly}(n-$ butyl acrylate) gives markedly improved photochromic performance in coloration and decoloration rates as well as greater optical density in the colored state when in a rigid crosslinked host matrix. In addition, placement of the dye in the middle of a polymer provided greater improvement than at the end [80]. Similarly, an optical data storage materials based on photochromic hydrogel of spironaphthoxazine was developed to show all photomode recording, as shown in Figure 11 [81].

3.2.3. Smart Textiles. Photochromic dyes, such as spirooxazines, are disperse dyes. Structurally, there are similarities with traditional disperse dyes for textiles in that they are small- to medium-size neutral molecules with a balance of hydrophilic and hydrophobic character. The major difference, however, is that they are nonplanar in their ring-closed form because the two ring systems of the molecules are connected through a spiro linkage ( $\mathrm{sp}^{3}$ carbon) so that they are orthogonal to one another.
Since the color change of these organic photochromic dyes is triggered by UV light, these dyes also have a UV protection function. Hence, applying photochromic dyes to a fabric can impart to the fabric, enhanced UV protection, smart fashion effects, functional effects such as camouflage, security printing, and for use in "smart" textile applications in general. In this prospective, recent research activity is growing for the application of photochromic compounds on textiles [82, 83].

The application of spirooxazines on polyamide fibers by exhaustion method at high temperature has been reported. However, the exhaustion percentage values of spiroxazine dyes were very low [84]. This exhaustion behavior was attributed to the low diffusional power of spiroxazine dyes within the higher crystalline structure of fiber molecules and the weak attractive forces between dyes and substrates. The observed results indicate that the dye exhaustion of spiroxazine dyeings which increased with increasing application temperatures was attributed to the higher kinetic energy of the spiroxazine molecules, the greater diffusional power within the polymer substrates, and the higher fiber swelling effect. In this context, it is thought that in terms of exhaustion temperature, the adsorption behavior of spiroxazine on polyamide substrates is following a similar dyeing mechanism as commercial nonionic dyes, which involved a highpressure and a high-temperature dyeing system. The result of dye exhaustion within the fiber molecules can be also supported from the photographs of the photochromism of the dyed substrates, as shon in Figure 12. These photographs were very useful to determine the spiroxazine penetration within the substrates and to confirm the photochromic reaction.

In an attempt to increase the exhaustion percentage and to better have wash fastness, disperse-reactive spirooxazine dyes containing dichlorotriazine were used for dyeing polyamide fabrics (Figure 13). Although successful fixation was observed, yet the exhaustion percentage remains very low [85].

Conventionally dyed photochromic fabric suffers from less dye uptake and low photochromic performance as a consequence of the rigid polymer matrix physically restricts the photochromic transformation. On the other hand, surface coating of photochromic microcapsules imparts a relatively harsh handle to the coated fabric.

Therefore, Sol-gel technique is thus the choice as it provides nanosized pores which can provide free space for photochromic transformations. In this interest, a thin film coating onto wool fabrics with spirooxazine photochromic dyes encapsulated in silica nanoparticles by sol-gel method resulted in better photochromic performance, good durability, and minimal influence on the fabric handle [86].

\section{Biomedical Applications and Fluorescent Sensors}

4.1. Photodynamic Therapy. Photodynamic therapy (PDT) is a light-activated treatment which is used in the clinic to destroy diseased tissues [87-89] and is in trials for 


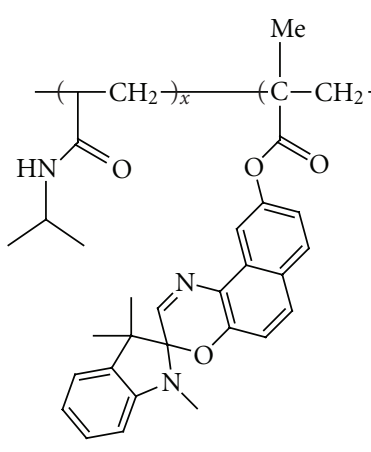

Spirooxazine form

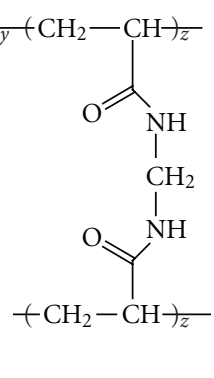

(a)

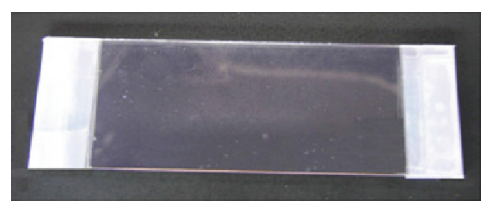

Cooling Heating

(b)



Reerasing $\uparrow$ Visible light

(e)



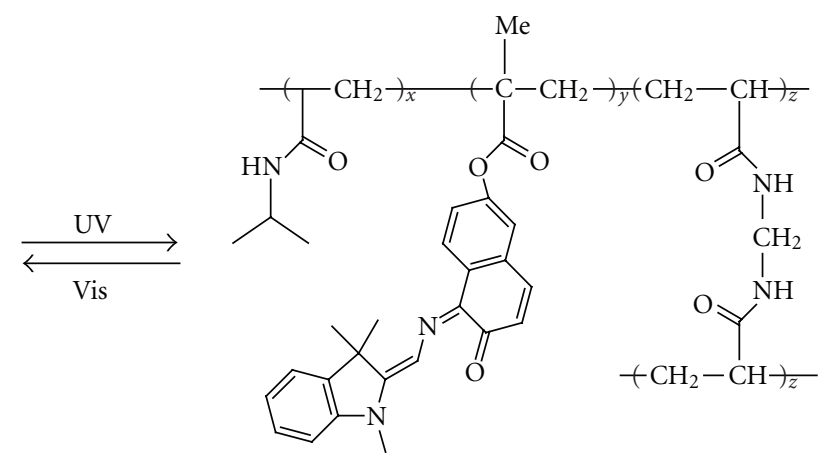

Photomerocyanine form (c)



FIgURe 11
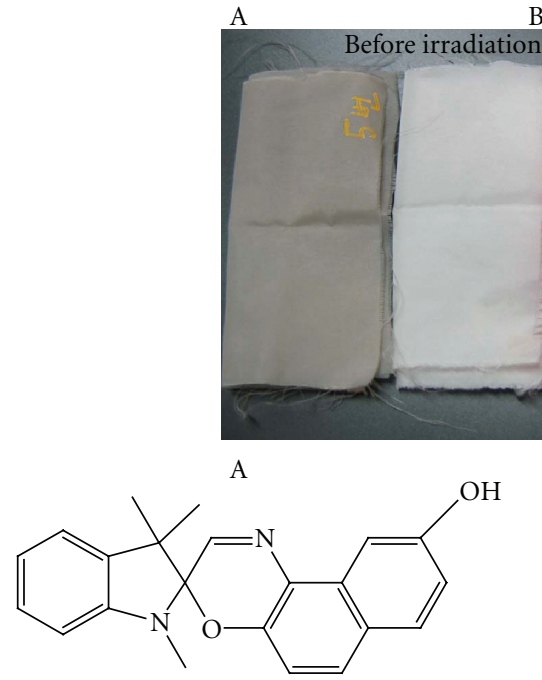
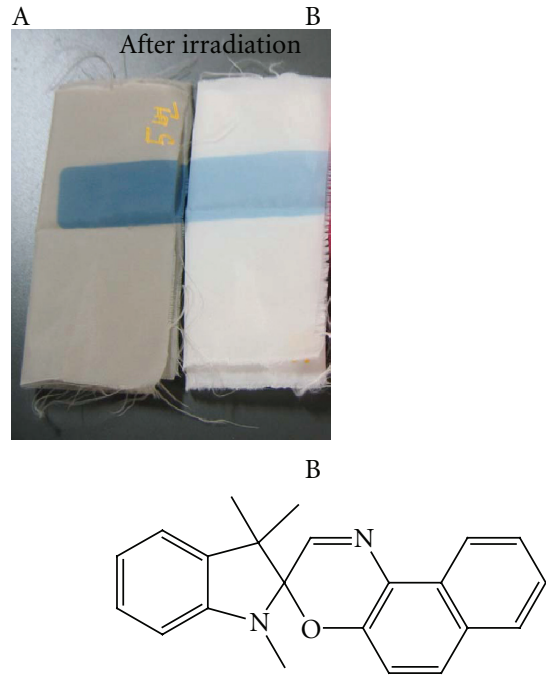

FIGURE 12 


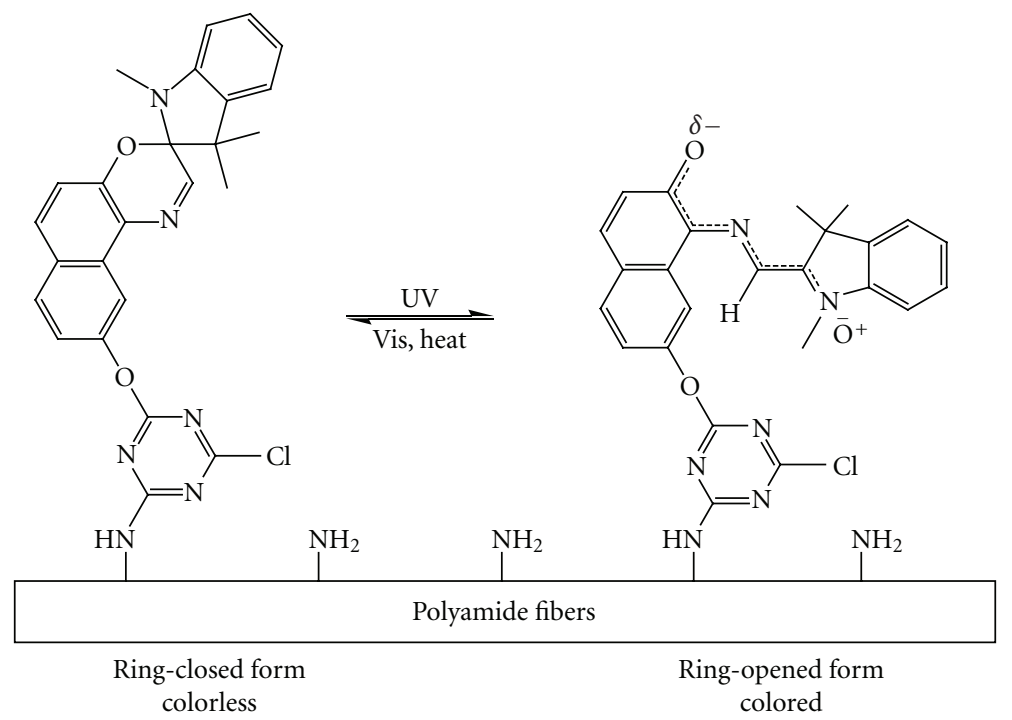

FIGURE 13: Reversible photoconversion structures between ring-closed colorless and ring-opened colored spiroxazine forms.

the eradication of localised bacterial infections [89]. The photodynamic action arises from the combined use of a photosensitiser and a light dose; independently, each of these components is harmless. The dual selectivity of the treatment is achieved through preferential uptake of the photosensitiser by diseased tissues and by controlled delivery of the light [90].

4.1.1. Photosensitizers, Design, and Mechanism. Dyes and pigments selectively absorb or transmit/reflect wavelengths of visible light and thus allow the perception of color in everyday life. In terms of light absorption, this depends on electronic transitions within the dye chromophore; thus certain dye types may only absorb specified wavelengths of light, depending on the relative dispositions of the electronic singlet ground and excited state energy levels.

Promoted electrons generally revert to the ground state via a mixture of nonradiative processes. Those which do not follow this route include fluorescent and phosphorescent dyes which lose energy, in part, by light emission and photosensitizing dyes which can use the excitational energy for reaction. Electronically, the main difference between photosensitiser molecules and other dye types is that the absorbed light energy can be passed on efficiently to other molecules in the vicinity or be utilised for photochemical reaction. The electronically excited photosensitizer molecule (singlet excited state) is relatively stable and can undergo an electronic rearrangement (to the excited triplet state, 3Ps*) (Figure 14).

Excitational energy transfer from the triplet state to other molecules facilitates photodynamic action through two types. Type I photosensitization involves direct interaction of the excited triplet state of the photosensitiser with adjacent molecules allowing electron transfer or hydrogen abstraction and the formation of reactive/radical species, for example, hydrogen peroxide, hydroxyl radicals, hydroperoxides and superoxide. Type II photosensitization involves direct transfer of the excitational energy from the triplet-excited state to ground state oxygen causes the formation of a highly reactive species, singlet oxygen (Figure 14). The formation of highly labile singlet oxygen within a cellular environment leads to non-specific oxidative reactions over a very short timescale; singlet oxygen will decay to the nontoxic ground state (triplet oxygen) within microseconds.

Photosensitizer action thus is aided by a relatively long-lived singlet excited state, since this is required for intersystem crossing to occur and populate the triplet excited state. However, this must also be sufficiently stable to allow type I reaction (electron transfer to the environment) or type II reaction (energy transfer to the triplet oxygen) rather than photodecaying via phosphorescence (Figure 14).

The quantity of singlet oxygen generated by a photosensitizer in type II is regulated by the efficiency of a spin-forbidden electronic transition from a singlet to a triplet state (ISC). Chemically this entails the inclusion in the chromophoric moiety of heavy atoms and is normally achieved by the substitution of chromophoric protons by lower group halogens (usually bromine or iodine) or lower group replacement of heteroatoms (e.g., sulphur for oxygen, selenium for sulphur, etc.). The introduction of a heavy atom into a molecule is known to have an influence over the rates of the ISC and is termed the heavy-atom effect [91-93].

On the other hand, it would be advantageous to have control over absorbance wavelength, as it could be envisaged that different tissue types would require different excitation wavelengths dependent upon tissue location (deep-seated tumors versus skin lesions), size, density, and pigmentation. The depth of light penetration through tissue is directly related to wavelength [94].

The depth that light penetrates into tissue is dependent upon the optical properties of the tissue and the wavelength of the light. At wavelengths longer than $900 \mathrm{~nm}$ water 


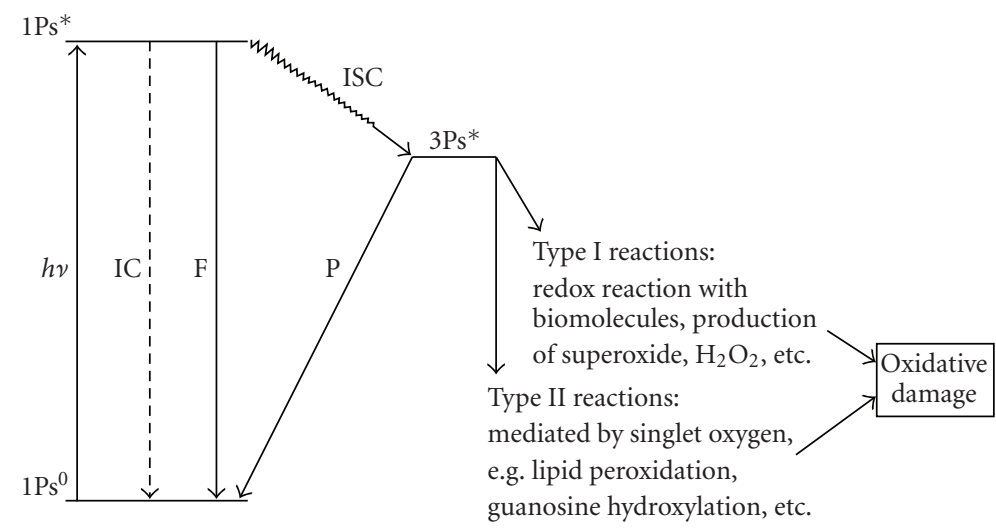

FIGURE 14: Photosensitization pathways: $1 \mathrm{Ps}^{0}$, ground singlet state of photosensizer molecule; $1 \mathrm{~s}^{*}$, excited singlet state; $h v$, light; IC, internal conversion; F, fluorescent decay; P, phosphorescent decay; ISC, inter-system crossing; 3Ps*, excited triplet state.

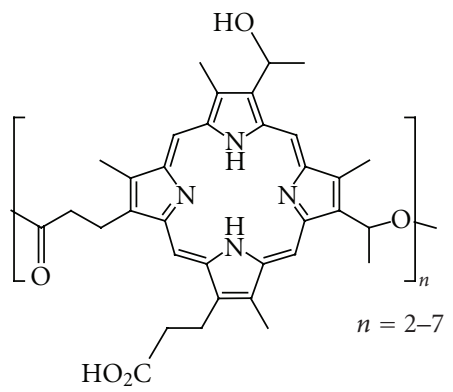

Photofrin

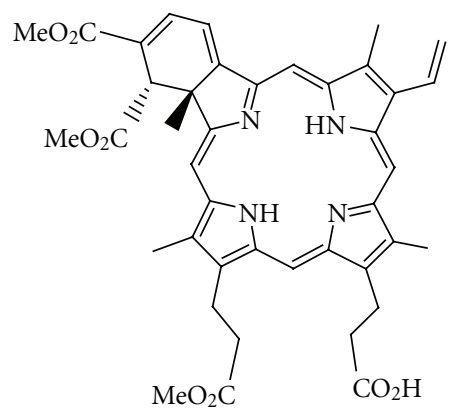

Verteporfin

Figure 15

starts to absorb, whereas at wavelengths less than $700 \mathrm{~nm}$ scattering by macromolecules is significant, and absorption by endogenous chromophores, such as haemoglobin, becomes dominant at wavelengths below $650 \mathrm{~nm}[95,96]$. The ideal drug is one which can be activated at wavelengths in the near infrared region, called the "therapeutic window" (700-950 nm), where the absorbance of biological tissues is minimal [96-99]. Wavelengths beyond $600 \mathrm{~nm}$ are used to excite clinical porphyrin-based PDT photosensitisers such as Photofrin $(630 \mathrm{~nm})$ or verteporfin $(690 \mathrm{~nm})$ (Figure 15) [100-102].

Photofrin was the first and at the present time remains the most common, clinically used PDT agent. Although it has been approved for use in the United States, Canada, Japan, and Europe for the treatment of esophageal, endobroncheal, bladder, lung, stomach, cervical, and skin cancers [89], it is widely recognized that it is far from being an ideal drug for use in PDT [103]. The investigation of porphyrin photosensitizers for the development of novel PDT agents has been extensive. Recently, some new hydrophilic conjugated porphyrin dimmers absorbed at $\lambda \max 700-800 \mathrm{~nm}$ have been reported [104].

4.1.2. Cyanine Dyes for PDT. Several inconvenients have been appeared over the last years upon using different photosensitizers as a PDT, and these may be due to the poor quantum yield of singlet oxygen generation, the weak absorption in the therapeutic window (700-950 nm), where optimal penetration of light into tissue is afforded, and/or the incompatibility of photosensitizer with patients cells.

Cyanine dyes have strong absorption $\left(\varepsilon>10^{5} \mathrm{M}^{-1} \mathrm{~cm}^{-1}\right)$ and can be tuned by structure variations to absorb at wavelengths in the near infrared region at the so- called phototherapeutic window of PDT. Hence, cyanine as cationic sensitizers for PDT seems to be a promising solution for the above mentioned inconvenients.

Cyanine dyes consist of two heterocyclic nuclei containing nitrogen centers linked through an odd number of methine bonds, which are normally in the trans conuration, in such a way that resonance occurs through the conjugated system between the tertiary and quaternary nitrogen atoms. The carbon atoms of the methine groups may be attached to groups other than hydrogen, or may be part of carbocyclic or heterocyclic ring systems. Certain cyanine dyes such as merocyanines and ketocyanines have been studied extensively as potential photosensitizers for photodynamic therapy PDT [105-107] and as radiation sensitizers [108] for solid tumor treatment.

In this respect, the chemical structure of merocyanine MC540 (Figure 16) is appealing to the medicinal chemist 


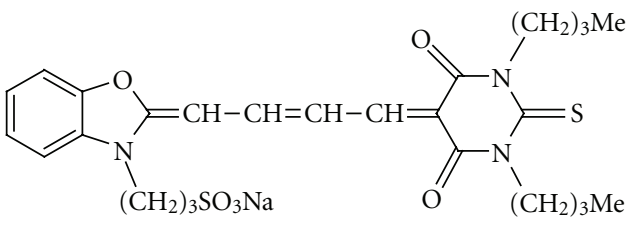

MC540

FIGURE 16

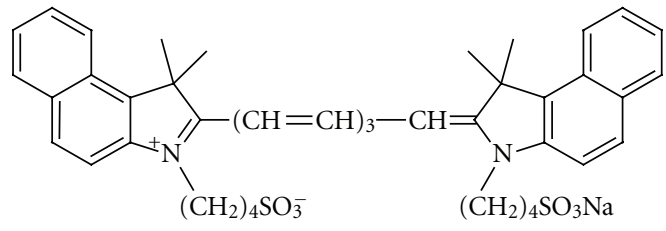

Indocyanine green

FIgURE 17

as it offers much scope for functionalisation. Thus, ring heteroatom exchange for one of higher atomic number (e.g., oxygen for sulphur) unsurprisingly leads to increased singlet oxygen yields [109].

The use of heavy atoms also stabilises the polymethine chain to photoisomerisation (a major deactivation pathway) [107]. As expected, varying the $\mathrm{N}$-alkyl side-chains in MC540 facilitates changes in the lipophilicity of the system [110]. In addition, lengthening the polymethine chain allows significant bathochromic shifts to be obtained.

Cyanine photosensitisers such as Indocyanine Green (Figure 17). exhibit long wavelength absorption in the $770 \mathrm{~nm}$ region [91].

The investigation of cyanine photosensitizers for the development of novel PDT agents has been growing. Recently, some new azo-cyanine (delocalized cationic azo dyes, as shown in Figure 18) with strong molar absorptivity around $700 \mathrm{~nm}$ and negative solvatochromism has been reported [111].

It has been reported that the substitution of one of the oxygen atoms of the central four member ring with amino group enhanced the production of singlet oxygen [112]. In this interest, several squarylium cyanine dyes derived from benzothiazole, benzoselenazole, and quinoline were synthesised and the central four-member ring is functionalized by substitution of one of the oxygen atoms by benzylamine, aniline, 3-iodoaniline, N,N-dimethylhydrazine and 2-aminosulfonic acid groups (Figure 19). All of the ensuing, novel aza-substituted dyes displayed strong absorption within the range $651-709 \mathrm{~nm}$ [113].

4.2. Fluorescent Sensors. The practical importance of functional dyes used in optical chemical sensor development has received increased attention in recent years. Fluorescent sensors represent a versatile tool for visualizing specific<smiles>[R1]c1ccc2c(c1)[Z](/C=C/c1cnc(/N=N/c3ccc(NCC)cc3)s1)=[N+]2[R8]</smiles>

$$
\begin{array}{ll}
\mathrm{Z}=\mathrm{S} & \mathrm{R}_{2}=\mathrm{C}_{2} \mathrm{H}_{5} \\
\mathrm{R}_{1}=6-\mathrm{I} & \mathrm{R}_{3}=\mathrm{CH}_{3}
\end{array}
$$

(a)

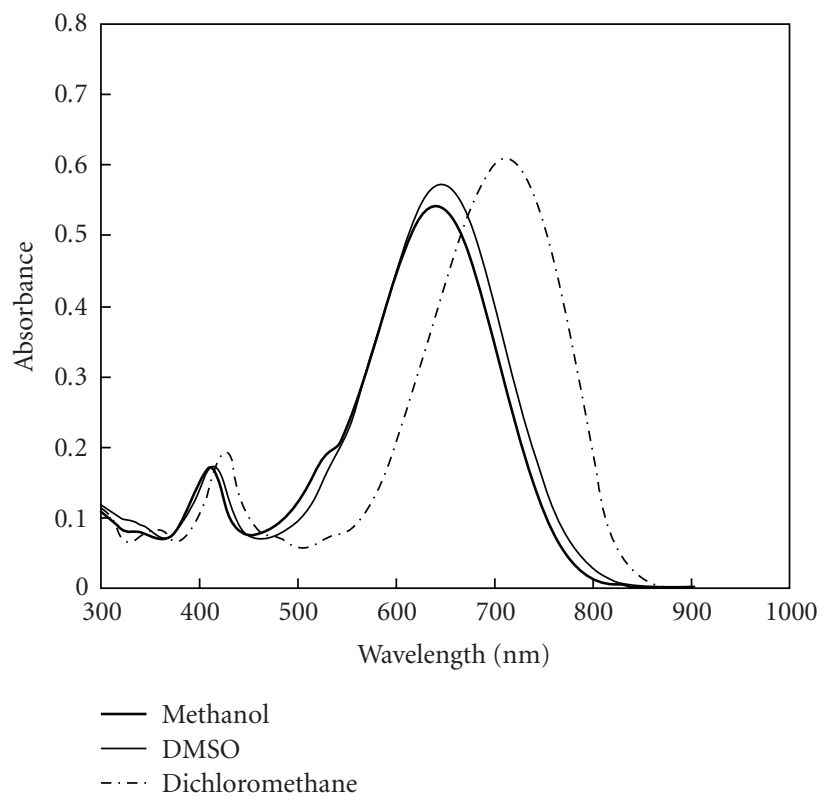

(b)

Figure 18

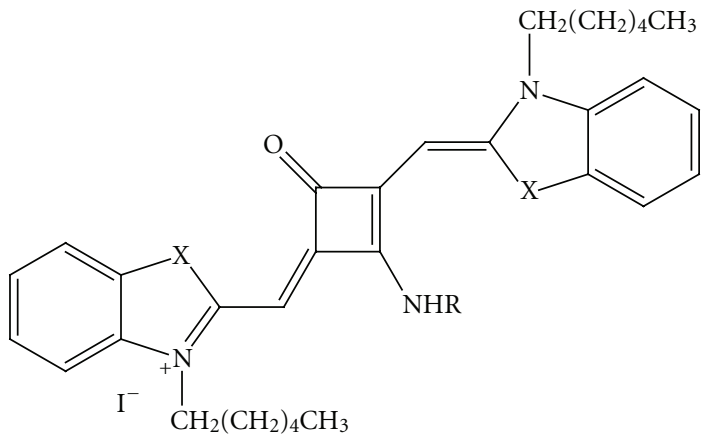

FIGURE 19

molecular targets and events in vitro and increasingly in vivo [114-116]. As a consequence, an increasingly large number of fluorescent sensors, available in different colors, are required [117].

A fluorescence-based technique for sensor applications offers significant advantages over other techniques due to its generally nondestructive character, high sensitivity, 

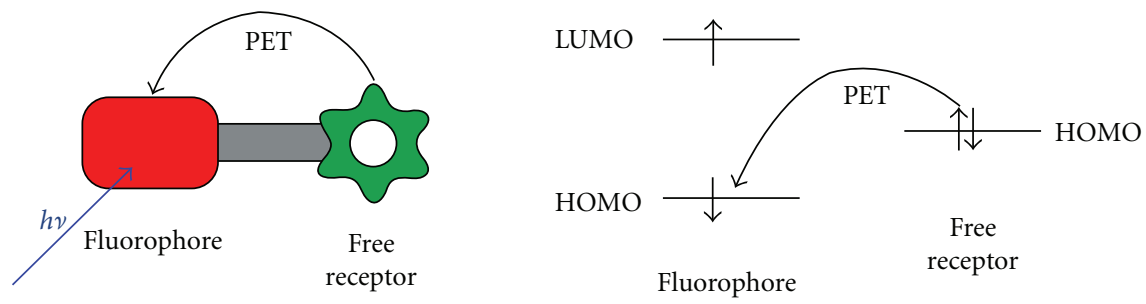

(a)

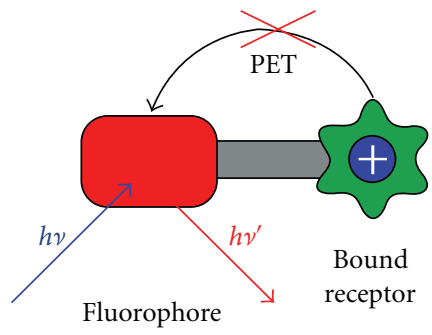

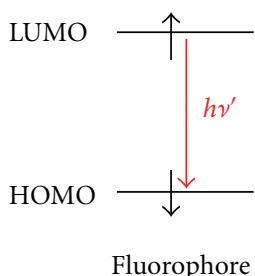

Fluorophore

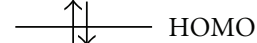

Bound

receptor

(b)

Figure 20: Principle of the PET chemically driven luminescent molecular switch. The HOMO level of the unbound receptor acts as an electron donor and effectively quenches the fluorescence of the reporter moiety (a). Upon coordination of the substrate, the energy of the HOMO level of the receptor is decreased because of electrostatic interaction with cationic species, and PET quenching is no longer possible (b).

and specificity. Chemosensors are molecules or molecular systems changing their optical or electrical properties upon interaction with small anions, cations, or neutral molecules.

4.2.1. Fluorescent Sensor, Design, and Mechanism. Chemically driven molecular switches usually molecules comprise three main building blocks: receptor moiety, linker (spacer), and the reporter moiety. Receptor moieties are specially designed binding sites for triggering ions or molecules. They should exhibit desirable selectivity and sensitivity toward selected triggers. The linker, in turn, should provide electronic communication between the receptor and reported moieties.

There are three main ways of providing sufficient electronic communication: (i) bridge providing overlap of $\pi$-systems of both moieties, (ii) short $\sigma$-spacer enabling photoinduced electron transfer, or (iii) arrangement of receptor and reporter using some supramolecular interactions providing perturbation of electronic structure of the reported moiety [118].

The most chemical switches with optical readout are usually based on the following photophysical phenomena: photoinduced electron transfer (PET) and photoinduced charge transfer (PCT).

4.2.2. Photoinduced Electron Transfer (PET). The principle of the PET-based chemical switch is shown in Figure 20. In most cases, the switch consists of a receptor, which selectively and reversibly binds a trigger, a fluorophore that provides optical communication between the switch and the environment, and a linker [117] that binds both components together and provides electronic communication between the receptor and the fluorophore (or chromophore) if the process is thermodynamically and kinetically feasible [119].

Importantly, the rate of electron transfer is much faster than the luminescence when PET is thermodynamically allowed (Figure 20(a)), and the luminescence of the fluorophore moiety is then quenched. Binding of the trigger to the receptor drastically alters the thermodynamics to the endoergonic situation (Figure 20(b)), and luminescence is not quenched any longer.

PET-based luminescent switches may be triggered by various chemical and physical stimuli: protons, metal cations, anions, neutral organic molecules, and even nanoparticles. Depending on the desired spectral properties and lifetime of the fluorescent switch, the molecular assembly may include various organic (anthracene, pyrene, naphthalimides, pyromellitimide, coumarins, fluoresceins, pyrazolobenzothiazoles, and diphenylpyrazoles) or inorganic fluorophores (polypyridine RuII complexes and lanthanide complexes) $[119,120]$. Selectivity and sensitivity of the chemosensors are controlled in turn by careful design of the receptor part. The large diversity of possible organic ligands enables designing of the sensors suited for particular applications. In the simplest case, the change of the energetics of the system is caused by electrostatic and electronic interactions between the receptor and the substrate.

If the trigger ion is an open shell transition metal ion, the quenching occurs upon binding as PET involves the 
<smiles>CCN(CC)c1c2ccccc2c(Cl)c2ccccc12</smiles>

SWITCH-1<smiles>c1ccc2c(COCc3ccncc3)c3ccccc3cc2c1</smiles>

SWITCH-2<smiles>CCc1c2ccccc2c(N2CCOCCOCCOCCOCC2)c2ccccc12</smiles>

SWITCH-3



SWITCH-4<smiles>O=C(O)CN(CC(=O)O)Cc1c2ccccc2c(CN(CC(=O)O)CC(=O)O)c2ccccc12</smiles>

SWITCH-5<smiles>COC1NC2C(OC)C(NC(=O)c3c4ccccc4cc4ccccc34)NC1C2OC</smiles>

SWITCH-7<smiles>Cn1c2ccccc2c(=O)c2cc3c(cc21)c(=O)c1ccccc1n3CNCCN</smiles>

SWITCH-6



FIgURE 21

$d$ orbitals of the metal center. Although most of the PET switches are triggered by protons or closed shell cations work in OFF/ON fashion (i.e., fluorescence is switched on upon binding of the trigger), careful design of the receptorfluorophore systems also gave the ON/OFF switch, as shown in Figure 21.

Two anthracene-based switches show this phenomenon. Tertiary aliphatic amines are efficient quenchers of anthracene emission, upon the protonation of which the fluorescence is observed, as in the case of molecule SWITCH-1. Exchange of the aliphatic amine for pyridine moiety yields the ON/OFF switch: protonated amine becomes an efficient quencher (SWITCH-2) [121].

The fluorescence can also be easily switched on with lithium and other alkali metal cations (SWITCH-3) [122]. Combination of $p$-toluenesulfonamido-quinoline with azacrown yields a very good switch responding selectively to $\mathrm{Zn}^{2+}$ cations (SWITCH-4) [123]. On the same principle, a PET-based switch activated with $\mathrm{Cd}^{2+}$ was constructed from the anthracene fluorophore bearing two aminoacid side arms (SWITCH-5) [124].

The opposite effect (ON/OFF switching on ion binding) was observed in the case of the fluorescent switch based on quinacridone skeleton with two diamine pendant arms (SWITCH-6) [125]. The arms have long saturated flexible chains, and the amino groups are far away from the fluorophore. Coordination of metal ions $\left(\mathrm{Cu}^{2+}, \mathrm{Hg}^{2+}, \mathrm{Zn}^{2+}\right.$, $\mathrm{Co}^{2+}$, and $\mathrm{Ni}^{2+}$ ) changes the geometry of the pendant arms, the metal ion localizes in close proximity of the central aromatic ring, and fluorescence is quenched due to photoinduced energy and/or electron transfer. A similar effect was observed in the case of the anthracene fluorophore linked via the amido bond with all-cis-2,4,6-triamino-1,3,5trihydroxycyclohexane (SWITCH-7) [126].

Extremely intense $(\Phi \approx 0.99)$ fluorescence of alkylsubstituted perylene tetracarbonyl bis-imide (SWITCH8) can be effectively switched on by protonation of the aniline moiety. 

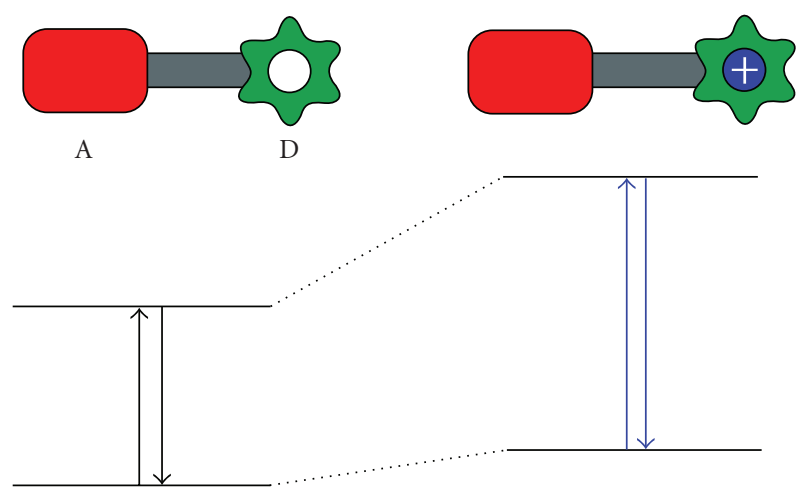

(a)
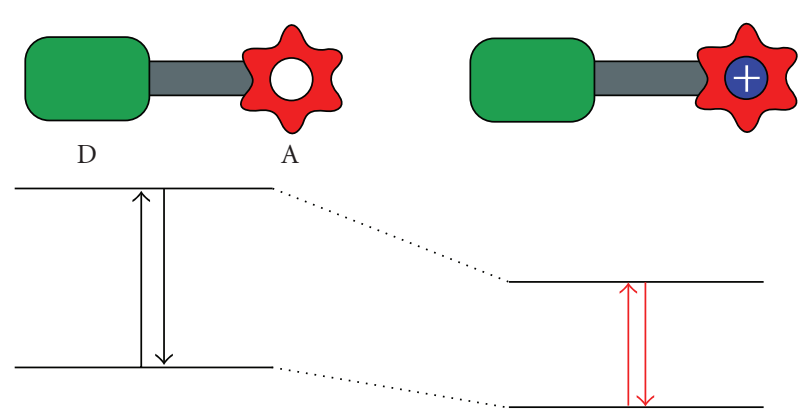

(b)

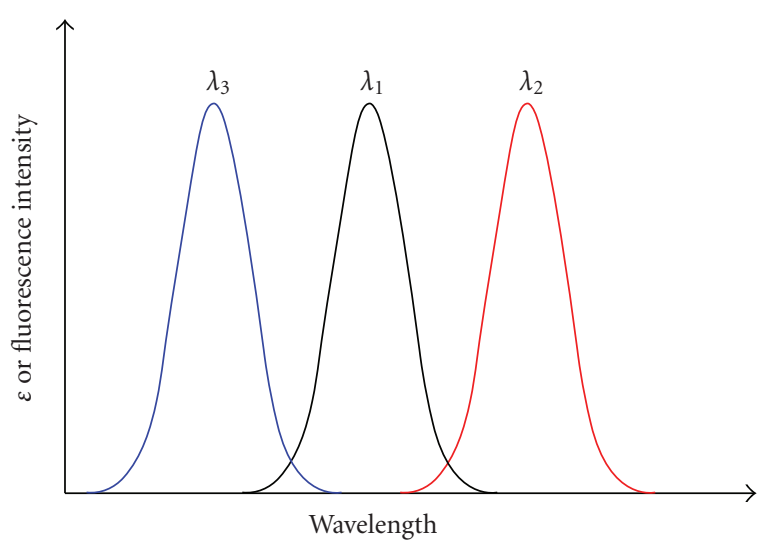

(c)

FIgure 22: Principle of the PCT chemically driven luminescent molecular switch based on the donor-spacer-acceptor architecture. Binding of cationic trigger to the donor (green) moiety results in the hypsochromic shift of absorption (emission) band (a), and binding of the same trigger to the acceptor moiety (red) results in bathochromic shift of the corresponding transition (b). The multireceptor system may exhibit both bathochromic and hypsochromic shifts upon binding different trigger ions (c), which results in a multistate molecular switch.

Furthermore, its fluorescence can be switched on upon interaction with various molecules and particles. Reaction with aldehydes or attachment to $\mathrm{TiO}_{2}$ nanoparticles activates the fluorescence [127].
4.2.3. Photoinduced Charge Transfer (PCT). Another large category of chemically driven optical switches encompasses the PCT systems. The principle of the PCT-based chemical switch is shown in Figure 22. In contrast to PET-based switches, the receptor and fluorophore (chromophore) moieties are connected in a way that provides extensive orbital delocalization between these two parts. One end of such a molecule is electron rich, while the other is electron poor; upon interaction with the environment, the electron distribution may significantly change, thus changing the optical properties of the switch.

In such push-pull systems, excitation leads to redistribution of electron density and generation of dipole moment. If the receptor binds a charged trigger species, the additional charge interacts with the photogenerated dipole, thus modifying the fluorescence spectrum. Repulsive interaction results in the hypsochromic shift (Figure 22(a)) of absorption and emission bands, while attraction results in bathochromic shift (Figure 22(b)). As shown in Figures 20 and 21 PET switches are not a donor- $\pi$-acceptor and mainly composed of fluorophore, spacer, and receptor whereas PCT switches are receptor/fluorophore in a donor- $\pi$-acceptor system, as shown in Figures 22 and 23. Therefore, the main advantage of PCT switches over PET switches consists in the possibility of usage of several wavelengths to analyze the state of the switch due to the color change upon cation sensing. PCT-based switches can be derived from well-known $\mathrm{pH}$ colorimetric indicators [128]. Very recently, similar systems, based on donor-acceptor-donor systems, as $\mathrm{Hg}^{2+}$ ion driven molecular switches have been reported [129, 130]. These switches (Figure 23) bear central acceptor moieties: 1,8naphthyridine (SWITCH-9) or squaraine coupled with two identical donor fragments: 1,4-dioxa-7,13-dithia-10 azacyclopentadecane (SWITCH-10).

The naphthyridine-based SWITCH-9 shows a strong absorption band at $450 \mathrm{~nm}$. Binding of one mercury equivalent increases the asymmetry of electron distribution within the molecule, which in turn results in the bathochromic shift of the lowest energy absorption band. Binding of the second mercury ion results in turn in a hypsochromic shift of the low-energy band due to interaction of bound cations with photoinduced dipole moments. This switch, due to low binding constant, requires high concentrations of triggering cation [129].

Dithiazacrown receptors are characterized by a very high affinity toward mercury ions, and even very low concentrations are sufficient to trigger optical changes of the squaraine-based switch (SWITCH-10). Binding of $\mathrm{Hg}^{2+}$ ions results in a gigantic hypsochromic shift from 650 to $285 \mathrm{~nm}$ [130].

4.2.4. Cyanine Marker for DNA. Fluorescent marker technology is a process that fluorescent compound is combined with the labeled-object by physical or chemical action to form a complex. By detecting the fluorescence intensity, the message of the labeled object is transferred qualitatively or quantitatively. As one of the widely used fluorescent labeling compounds (fluorescence dye sensor), fluorescent dyes have many advantages, such as fast detection 
<smiles>OCCN(CCO)c1ccc(C#Cc2ccc3ccc(C#Cc4ccc(N(CCO)CCO)cc4)nc3n2)cc1</smiles>

Figure 23



3a $\mathrm{R}=\mathrm{CH}_{2} \mathrm{CH}_{2} \mathrm{SO}_{3}^{\ominus}$ inner salt

(a)

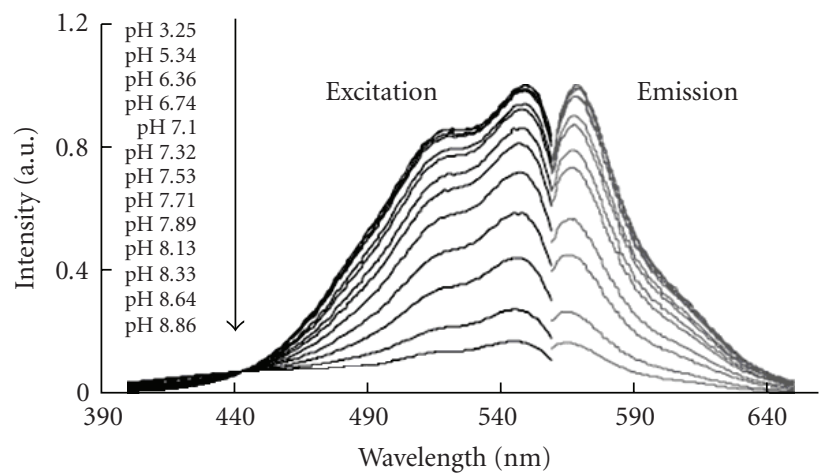

(b)

Figure 24: Excitation and emission spectra of dye $3 \mathrm{a}\left(5 \times 10^{-6} \mathrm{M}, \lambda_{\mathrm{ex}}=550 \mathrm{~nm}\right.$ and $\left.\lambda_{\mathrm{em}}=569 \mathrm{~nm}\right)$ in aqueous buffer solutions at $25^{\circ} \mathrm{C}$ as a function of $\mathrm{pH}$.

speed, good repetitiveness, low dosage, and nonradiation [131].

Determination of nucleic acids is required in many fields, such as molecular biology, biotechnology, and medical diagnosis. As mentioned above fluorescence-based technique for the detection of nucleic acids offers significant advantages over other techniques due to its high sensitivity and specificity. Nucleic acids by themselves are nonfluorescent and thus they need to be bound with certain fluorescent probes such as cyanine dyes. Due to their excellent staining properties, cyanine dyes have been utilized in biological applications such as the detection of DNA [132-138]. The main advantage of these dyes is that they become strongly fluorescent after binding with nucleic acids $[139,140]$. Two possible types of interaction with nucleic acids, intercalation, and electrostatic binding have been proposed [141]. This huge enhancement in fluorescence is believed to originate from the loss of mobility around the methine bridge between the two heterocyclic moieties [142].

4.2.5. Cyanine $p H$ Sensor. The excitation and emission spectra of cyanine fluorescent sensors span the visible and NIR spectra from $450 \mathrm{~nm}$, where autofluorescence from biomolecules is greatly reduced, up to $800 \mathrm{~nm}$. Biochemical processes frequently involve protonation and deprotonation of biomolecules with concomitant changes in the $\mathrm{pH}$ of the medium. Consequently, there has been an increase in the use of $\mathrm{pH}$-sensitive fluorescent probes for intracellular studies [143]. In this interest, the use of cyanine dyes as fluorescent $\mathrm{pH}$ sensor has been growing [144-146].

Recently, new cyanine fluorescent $\mathrm{pH}$ sensors have been reported [147]. The result indicated that these dyes are 
suitable for biological applications as they are sensitive to the changes of the intracellular $\mathrm{pH}$ range (6-8). It was suggested that the intense cyanine dye absorption and emission properties were largely due to the resonance effect between the two nitrogen atoms of the two indole rings via the conjugated polymethine bridge; abstraction of a proton from this system destroyed this resonance and subsequently leaded to the nonfluorescent base form (Figure 24).

\section{Conclusions and Perspectives}

(1) The natural light harvesting complexes of plants are one of the most fascinating functional molecular assemblies. Scientists are yet to challenge and to mimic the nature in harvesting the solar energy. As we have seen, solar energy conversion using DSCs is possible; however future research work in this field is required to better have the suitable molecular design of sensitizers.

(2) The investigations presented in this review clearly indicate that information processing at the molecular level is possible using photochromic dyes and remained to be developed in the thermal stability of the photochromes so as to have all light responsive function.

(3) The use of photochromic dyes in the coloration of textile is in its fancy stage and it is anticipated that this trend in combination with nanotechnology will get more effective in the production of smart textiles.

(4) Also, some success in the field of photodynamic therapy has been made using functional dyes and future development is needed to design photosenitizers able to selectively interact with the tissue and with high productivity of singlet oxygen.

(5) Last but not least, known small-molecule fluorophores have a wide range of spectral and chemical properties. Elaboration of these core structures has provided numerous sensors for analytes and for assaying biological systems. Nonetheless, extraordinary opportunities remain, because delving deeper into biochemical and biological phenomena will require ever more sophisticated and tailored sensors.

\section{References}

[1] Z. Yoshida and T. Kitao, Chemistry of Functional Dyes, Mita Press, Tokyo, Japan, 1989.

[2] J. Barber and B. Andersson, "Revealing the blueprint of photosynthesis," Nature, vol. 370, no. 6484, pp. 31-34, 1994.

[3] V. Balzani, A. Credi, and M. Venturi, "Photoprocesses," Current Opinion in Chemical Biology, vol. 1, no. 4, pp. 506513, 1997.

[4] V. Balzani, A. Credi, and M. Venturi, "Photoinduced charge separation and solar energy conversion," in Molecular Devices and Machines: A Journey into the Nanoworld, pp. 132-173, Wiley-VCH, Weinheim, Germany, 2003.
[5] T. Pullerits and V. Sundström, "Photosynthetic lightharvesting pigment-protein complexes. Toward understanding how and why," Accounts of Chemical Research, vol. 29, no. 8, pp. 381-389, 1996.

[6] T. Ritz, A. Damjanović, and K. Schulten, "The quantum physics of photosynthesis," ChemPhysChem, vol. 3, no. 3, pp. 243-248, 2002.

[7] M. A. Green, "Third generation photovoltaics: ultra-high conversion efficiency at low cost," Progress in Photovoltaics, vol. 9, no. 2, pp. 123-135, 2001.

[8] B. O'Regan and M. Grätzel, "A low-cost, high-efficiency solar cell based on dye-sensitized colloidal $\mathrm{TiO}_{2}$ films," Nature, vol. 353, no. 6346, pp. 737-740, 1991.

[9] M. Grätzel, "Perspectives for dye-sensitized nanocrystalline solar cells," Progress in Photovoltaics, vol. 8, no. 1, pp. 171$185,2000$.

[10] M. Grätzel, "Photoelectrochemical cells," Nature, vol. 414, no. 6861, pp. 338-344, 2001.

[11] S. Günes and N. S. Sariciftci, "Hybrid solar cells," Inorganica Chimica Acta, vol. 361, no. 3, pp. 581-588, 2008.

[12] G. P. Kalaignan and Y. S. Kang, "A review on mass transport in dye-sensitized nanocrystalline solar cells," Journal of Photochemistry and Photobiology C, vol. 7, no. 1, pp. 17-22, 2006.

[13] A. Hagfeldt and M. Grätzel, "Molecular photovoltaics," Accounts of Chemical Research, vol. 33, p. 269, 2000.

[14] M. K. Nazeeruddin, F. De Angelis, S. Fantacci, et al., "Combined experimental and DFT-TDDFT computational study of photoelectrochemical cell ruthenium sensitizers," Journal of the American Chemical Society, vol. 127, no. 48, pp. 16835-16847, 2005.

[15] M. K. Nazeeruddin, P. Péchy, T. Renouard, et al., "Engineering of efficient panchromatic sensitizers for nanocrystalline $\mathrm{TiO}_{2}$-based solar cells," Journal of the American Chemical Society, vol. 123, no. 8, pp. 1613-1624, 2001.

[16] P. Gregory, High Technology Applications of Organic Colorants, Plenum, New York, NY, USA, 1991.

[17] K. Hara, T. Sato, R. Katoh, et al., "Molecular design of coumarin dyes for efficient dye-sensitized solar cells," Journal of Physical Chemistry B, vol. 107, no. 2, pp. 597-606, 2003.

[18] K. Sayama, K. Hara, N. Mori, et al., "Photosensitization of a porous $\mathrm{TiO}_{2}$ electrode with merocyanine dyes containing a carboxyl group and a long alkyl chain," Chemical Communications, no. 13, pp. 1173-1174, 2000.

[19] A. Ehret, L. Stuhl, and M. T. Spitler, "Spectral sensitization of $\mathrm{TiO}_{2}$ nanocrystalline electrodes with aggregated cyanine dyes," Journal of Physical Chemistry B, vol. 105, no. 41, pp. 9960-9965, 2001.

[20] T. Horiuchi, H. Miura, K. Sumioka, and S. Uchida, "High efficiency of dye-sensitized solar cells based on metal-free indoline dyes," Journal of the American Chemical Society, vol. 126, no. 39, pp. 12218-12219, 2004.

[21] Z.-S. Wang, F.-U. Li, and C.-H. Huang, "Highly efficient sensitization of nanocrystalline $\mathrm{TiO}_{2}$ films with styryl benzothiazolium propylsalfonate," Chemical Communications, no. 20, pp. 2063-2064, 2000.

[22] M. Liang, W. Xu, F. Cai, et al., "New triphenylamine-based organic dyes for efficient dye-sensitized solar cells," Journal of Physical Chemistry C, vol. 111, no. 11, pp. 4465-4472, 2007.

[23] M. Velusamy, K. R. J. Thomas, J. T. Lin, Y.-C. Hsu, and K.-C. Ho, "Organic dyes incorporating low-band-gap chromophores for dye-sensitized solar cells," Organic Letters, vol. 7, no. 10, pp. 1899-1902, 2005. 
[24] M.-S. Tsai, Y.-C. Hsu, J. T. Lin, H.-C. Chen, and C.-P. Hsu, "Organic dyes containing $1 H$-phenanthro $[9,10-d]$ imidazole conjugation for solar cells," Journal of Physical Chemistry C, vol. 111, no. 50, pp. 18785-18793, 2007.

[25] K. R. J. Thomas, Y.-C. Hsu, J. T. Lin, et al., "2,3-disubstituted thiophene-based organic dyes for solar cells," Chemistry of Materials, vol. 20, no. 5, pp. 1830-1840, 2008.

[26] K. Hara, T. Sato, R. Katoh, et al., "Novel conjugated organic dyes for efficient dye-sensitized solar cells," Advanced Functional Materials, vol. 15, no. 2, pp. 246-252, 2005.

[27] S. Kim, J. K. Lee, S. O. Kang, et al., "Molecular engineering of organic sensitizers for solar cell applications," Journal of the American Chemical Society, vol. 128, no. 51, pp. 1670116707, 2006.

[28] H. Choi, J. K. Lee, K. Song, S. O. Kang, and J. Ko, "Novel organic dyes containing bis-dimethylfluorenyl amino benzo[b]thiophene for highly efficient dye-sensitized solar cell," Tetrahedron, vol. 63, no. 15, pp. 3115-3121, 2007.

[29] H. Tian, X. Yang, R. Chen, et al., "Phenothiazine derivatives for efficient organic dye-sensitized solar cells," Chemical Communications, no. 36, pp. 3741-3743, 2007.

[30] R. Chen, X. Yang, H. Tian, and L. Sun, "Tetrahydroquinoline dyes with different spacers for organic dye-sensitized solar cells," Journal of Photochemistry and Photobiology A, vol. 189, no. 2-3, pp. 295-300, 2007.

[31] N. Koumura, Z.-S. Wang, S. Mori, M. Miyashita, E. Suzuki, and K. Hara, "Alkyl-functionalized organic dyes for efficient molecular photovoltaics," Journal of the American Chemical Society, vol. 128, no. 44, pp. 14256-14257, 2006.

[32] S. Y. Huang, G. Schlichthörl, A. J. Nozik, M. Grätzel, and A. J. Frank, "Charge recombination in dye-sensitized nanocrystalline $\mathrm{TiO}_{2}$ solar cells," Journal of Physical Chemistry B, vol. 101, no. 14, pp. 2576-2582, 1997.

[33] N. Satoh, T. Nakashima, and K. Yamamoto, "Metalassembling dendrimers with a triarylamine core and their application to a dye-sensitized solar cell," Journal of the American Chemical Society, vol. 127, no. 37, pp. 1303013038, 2005.

[34] E. Palomares, J. N. Clifford, S. A. Haque, T. Lutz, and J. R. Durrant, "Control of charge recombination dynamics in dye sensitized solar cells by the use of conformally deposited metal oxide blocking layers," Journal of the American Chemical Society, vol. 125, no. 2, pp. 475-482, 2003.

[35] P. Bonhôte, J.-E. Moser, R. Humphry-Baker, et al., "Longlived photoinduced charge separation and redox-type photochromism on mesoporous oxide films sensitized by molecular dyads," Journal of the American Chemical Society, vol. 121, no. 6, pp. 1324-1336, 1999.

[36] J. N. Clifford, G. Yahioglu, L. R. Milgrom, and J. R. Durrant, "Molecular control of recombination dynamics in dye sensitised nanocrystalline $\mathrm{TiO}_{2}$ films," Chemical Communications, vol. 126, no. 12, pp. 1260-1261, 2002.

[37] S. A. Haque, S. Handa, K. Peter, E. Palomares, M. Thelakkat, and J. R. Durrant, "Supermolecular control of charge transfer in dye-sensitized nanocrystalline $\mathrm{TiO}_{2}$ films: towards a quantitative structure-function relationship," Angewandte Chemie International Edition, vol. 44, no. 35, pp. 5740-5744, 2005.

[38] F. Zhang, Y. Luo, J. Song, et al., "Triphenylamine-based dyes for dye-sensitized solar cells," Dyes and Pigments, vol. 81, no. 3, pp. 224-230, 2009.
[39] F.-T. Kong, S.-Y. Dai, and K.-J. Wang, "Review of recent progress in dye-sensitized solar cells," Advances in OptoElectronics, vol. 2007, Article ID 75384, 13 pages, 2007.

[40] J.-H. Yum, D. P. Hagberg, S.-J. Moon, et al., "A light-resistant organic sensitizer for solar-cell applications," Angewandte Chemie International Edition, vol. 48, no. 9, pp. 1576-1580, 2009.

[41] C. Baik, D. Kim, M.-S. Kang, et al., "Organic dyes with a novel anchoring group for dye-sensitized solar cell applications," Journal of Photochemistry and Photobiology A, vol. 201, no. 2-3, pp. 168-174, 2009.

[42] Z. Ning, Q. Zhang, W. Wu, H. Pei, B. Liu, and H. Tian, "Starburst triarylamine based dyes for efficient dye-sensitized solar cells," Journal of Organic Chemistry, vol. 73, no. 10, pp. 3791-3797, 2008.

[43] S. Kim, J. K. Lee, S. O. Kang, et al., "Molecular engineering of organic sensitizers for solar cell applications," Journal of the American Chemical Society, vol. 128, no. 51, pp. 1670116707, 2006.

[44] D. P. Hagberg, T. Edvinsson, T. Marinado, G. Boschloo, A. Hagfeldt, and L. Sun, "A novel organic chromophore for dyesensitized nanostructured solar cells," Chemical Communications, no. 21, pp. 2245-2247, 2006.

[45] J. T. Lin, P.-C. Chen, Y.-S. Yen, Y.-C. Hsu, H.-H. Chou, and M.-C. P. Yeh, "Organic dyes containing furan moiety for high-performance dye-sensitized solar cells," Organic Letters, vol. 11, no. 1, pp. 97-100, 2009.

[46] C.-W. Lee, H.-P. Lu, C.-M. Lan, et al., "Novel zinc porphyrin sensitizers for dye-sensitized solar cells: synthesis and spectral, electrochemical, and photovoltaic properties," Chemistry-A European Journal, vol. 15, no. 6, pp. 14031412, 2009.

[47] G. Calogero and G. Di Marco, "Red Sicilian orange and purple eggplant fruits as natural sensitizers for dye-sensitized solar cells," Solar Energy Materials and Solar Cells, vol. 92, no. 11, pp. 1341-1346, 2008.

[48] N. J. Cherepy, G. P. Smestad, M. Grätzel, and J. Z. Zhang, "Ultrafast electron injection: implications for a photoelectrochemical cell utilizing an anthocyanin dye-sensitized $\mathrm{TiO}_{2}$ nanocrystalline electrode," Journal of Physical Chemistry B, vol. 101, no. 45, pp. 9342-9351, 1997.

[49] H. Durr and H. Bouas-Laurent, Eds., Photochromism: Molecules and Systems, Elsevier, New York, NY, USA, 1990.

[50] F. Pina and T. A. Hatton, "Photochromic soft materials: flavylium compounds incorporated into pluronic F-127 hydrogel matrixes," Langmuir, vol. 24, no. 6, pp. 2356-2364, 2008.

[51] B. L. Feringa, Molecular Switches, Wiley-VCH, Weinheim, Germany, 2001.

[52] F. M. Raymo and S. Giordani, "Multichannel digital transmission in an optical network of communicating molecules," Journal of the American Chemical Society, vol. 124, no. 9, pp. 2004-2007, 2002.

[53] H. Tian and S. Yang, "Recent progresses on diarylethene based photochromic switches," Chemical Society Reviews, vol. 33, no. 2, pp. 85-97, 2004.

[54] H. Tian and S. Wang, "Photochromic bisthienylethene as multi-function switches," Chemical Communications, no. 8, pp. 781-792, 2007.

[55] M. Irie, "Diarylethenes for memories and switches," Chemical Reviews, vol. 100, no. 5, pp. 1685-1716, 2000. 
[56] M. Irie, Ed., Photoreactive Materials for Ultrahigh-Density Optical Memory, Elsevier, Amsterdam, The Netherlands, 1994.

[57] J. C. Crano and R. J. Guglielmetti, Eds., Organic, Photochromic and Thermochromic Compounds, vol. 1, Plenum, New York, NY, USA, 1999.

[58] A. J. Myles, T. J. Wigglesworth, and N. R. Branda, "A multi-addressable photochromic 1,2-dithienylcyclopentenephenoxynaphthacene-quinone hybrid," Advanced Materials, vol. 15, no. 9, pp. 745-748, 2003.

[59] C. C. Corredor, Z.-L. Huang, and K. D. Belfield, "Twophoton 3D optical data storage via fluorescence modulation of an efficient fluorene dye by a photochromic diarylethene," Advanced Materials, vol. 18, no. 21, pp. 2910-2914, 2006.

[60] S.-J. Lim, J. Seo, and S. Y. Park, "Photochromic switching of excited-state intramolecular proton-transfer (ESIPT) fluorescence: a unique route to high-contrast memory switching and nondestructive readout," Journal of the American Chemical Society, vol. 128, no. 45, pp. 14542-14547, 2006.

[61] S.-J. Lim, B.-K. An, and S. Y. Park, "Bistable photoswitching in the film of fluorescent photochromic polymer: enhanced fluorescence emission and its high contrast switching," Macromolecules, vol. 38, no. 15, pp. 6236-6239, 2005.

[62] G. Jiang, S. Wang, W. Yuan, et al., "Highly fluorescent contrast for rewritable optical storage based on photochromic bisthienylethene-bridged naphthalimide dimer," Chemistry of Materials, vol. 18, no. 2, pp. 235-237, 2006.

[63] G. Berkovic, V. Krongauz, and V. Weiss, "Spiropyrans and spirooxazines for memories and switches," Chemical Reviews, vol. 100, no. 5, pp. 1741-1753, 2000.

[64] L. Gobbi, P. Seiler, F. Diederich, et al., "Photoswitchable tetraethynylethene-dihydroazulene chromophores," Helvetica Chimica Acta, vol. 84, no. 4, pp. 743-777, 2001.

[65] V. De Waele, U. Schmidhammer, T. Mrozek, J. Daub, and E. Riedle, "Ultrafast bidirectional dihydroazulene/vinylheptafulvene (DHA/VHF) molecular switches: photochemical ring closure of vinylheptafulvene proven by a two-pulse experiment," Journal of the American Chemical Society, vol. 124, no. 11, pp. 2438-2439, 2002.

[66] K. Matsuda and M. Irie, "Diarylethene as a photoswitching unit," Journal of Photochemistry and Photobiology C, vol. 5, no. 2, pp. 169-182, 2004.

[67] M. Tomasulo, S. Sortino, A. J. P. White, and F. M. Raymo, "Fast and stable photochromic oxazines," Journal of Organic Chemistry, vol. 70, no. 20, pp. 8180-8189, 2005.

[68] M. Tomasulo, S. Sortino, and F. M. Raymo, "A fast and stable photochromic switch based on the opening and closing of an oxazine ring," Organic Letters, vol. 7, no. 6, pp. 1109-1112, 2005.

[69] S. Jockusch, N. J. Turro, and F. R. Blackburn, "Photochromism of $2 H$-naphtho[1,2-b]pyrans: a spectroscopic investigation," Journal of Physical Chemistry A, vol. 106, no. 40, pp. 9236-9241, 2002.

[70] M. A. L. Sheepwash, R. H. Mitchell, and C. Bohne, "Mechanistic insights into the photochromism of trans-10b, 10cdimethyl-10b, 10c-dihydropyrene derivatives," Journal of the American Chemical Society, vol. 124, no. 17, pp. 4693-4700, 2002.

[71] Y. Yokoyama, "Fulgides for memories and switches," Chemical Reviews, vol. 100, no. 5, pp. 1717-1739, 2000.
[72] K. Szaciłowski, "Digital information processing in molecular systems," Chemical Reviews, vol. 108, no. 9, pp. 3481-3548, 2008.

[73] S. Pu, G. Liu, L. Shen, and J. Xu, "Efficient synthesis and properties of isomeric photochromic diarylethenes having a pyrrole unit," Organic Letters, vol. 9, no. 11, pp. 2139-2142, 2007.

[74] D.-Y. Yang, Y.-S. Chen, P.-Y. Kuo, et al., "Novel oxazabicycles as a new class of photochromic colorants," Organic Letters, vol. 9, no. 25, pp. 5287-5290, 2007.

[75] J.-R. Chen, J.-B. Wong, P.-Y. Kuo, and D.-Y. Yang, "Synthesis and characterization of coumarin-based spiropyran photochromic colorants," Organic Letters, vol. 10, no. 21, pp. 4823-4826, 2008.

[76] S. Kawata and Y. Kawata, "Three-dimensional optical data storage using photochromic materials," Chemical Reviews, vol. 100, no. 5, pp. 1777-1788, 2000.

[77] M. Irie and M. Mohri, “Thermally irreversible photochromic systems. Reversible photocyclization of diarylethene derivatives," Journal of Organic Chemistry, vol. 53, no. 4, pp. 803808, 1988.

[78] M. Giraud, A. Léaustic, R. Guillot, P. Yu, F. Maurel, and K. Nakatani, "Easy and efficient tuning of the photochromic properties of 1,2-bis [ $5^{\prime}$-methyl- $2^{\prime}-\left(2^{\prime \prime}\right.$ pyridyl)thiazolyl]perfluorocyclopentene," Tetrahedron Letters, vol. 50, no. 13, pp. 1485-1489, 2009.

[79] J. Yin, Y. Lin, X. Cao, G.-A. Yu, H. Tu, and S. H. Liu, "The synthesis and photochromic properties of two bis(phosphine) ligands based on dithienylethene backbone and their oxides, sulfurets and selenides," Dyes and Pigments, vol. 81, no. 2, pp. 152-155, 2009.

[80] N. Malic, J. A. Campbell, and R. A. Evans, "Superior photochromic performance of naphthopyrans in a rigid host matrix using polymer conjugation: fast, dark, and tunable," Macromolecules, vol. 41, no. 4, pp. 1206-1214, 2008.

[81] S. Wang, M.-S. Choi, and S.-H. Kim, "Bistable photoswitching in poly(N-isopropylacrylamide) with spironaphthoxazine hydrogel for optical data storage," Journal of Photochemistry and Photobiology A, vol. 198, no. 2-3, pp. 150155, 2008.

[82] S. M. R. Billah, R. M. Christie, and R. Shamey, "Direct coloration of textiles with photochromic dyes-part 1 : application of spiroindolinonaphthoxazines as disperse dyes to polyester, nylon and acrylic fabrics," Coloration Technology, vol. 124, no. 4, pp. 223-228, 2008.

[83] S. M. R. Billah, R. M. Christie, and K. M. Morgan, "Direct coloration of textiles with photochromic dyes-part 2: the effect of solvents on the colour change of photochromic textiles," Coloration Technology, vol. 124, no. 4, pp. 229-233, 2008.

[84] S.-J. Lee, Y.-A. Son, H.-J. Suh, D.-N. Lee, and S.-H. Kim, "Preliminary exhaustion studies of spiroxazine dyes on polyamide fibers and their photochromic properties," Dyes and Pigments, vol. 69, no. 1-2, pp. 18-21, 2006.

[85] Y.-A. Son, Y.-M. Park, S.-Y. Park, C.-J. Shin, and S.H. Kim, "Exhaustion studies of spiroxazine dye having reactive anchor on polyamide fibers and its photochromic properties," Dyes and Pigments, vol. 73, no. 1, pp. 76-80, 2007.

[86] T. Cheng, T. Lin, R. Brady, and X. Wang, "Photochromic fabrics with improved durability and photochromic performance " Fibers and Polymers, vol. 9, no. 5, pp. 521-526, 2008. 
[87] R. Bonnett, Chemical Aspects of Photodynamic Therapy, Gordon and Breach Science, Amsterdam, The Netherlands, 2000.

[88] T. J. Dougherty, C. J. Gomer, B. W. Henderson, et al., "Photodynamic therapy," Journal of the National Cancer Institute, vol. 90, no. 12, pp. 889-905, 1998.

[89] I. J. MacDonald and T. J. Dougherty, "Basic principles of photodynamic therapy," Journal of Porphyrins and Phthalocyanines, vol. 5, no. 2, pp. 105-129, 2001.

[90] M. R. Hamblin and T. Hasan, "Photodynamic therapy: a new antimicrobial approach to infectious disease?" Photochemical and Photobiological Sciences, vol. 3, no. 5, pp. 436-450, 2004.

[91] M. Wainwright, "Photodynamic therapy-from dyestuffs to high-tech clinical practice," Reverend Program Coloration, vol. 34, pp. 95-109, 2004.

[92] N. J. Turro, in Modern Molecular Photochemistry, pp. 191195, University Science, Sausalito, Calif, USA, 1991.

[93] A. Gorman, J. Killoran, C. O'Shea, T. Kenna, W. M. Gallagher, and D. F. O'Shea, "In vitro demonstration of the heavy-atom effect for photodynamic therapy," Journal of the American Chemical Society, vol. 126, no. 34, pp. 10619-10631, 2004.

[94] B. C. Wilson, M. S. Patterson, and L. Lilge, "Implicit and explicit dosimetry in photodynamic therapy: a new paradigm," Lasers in Medical Science, vol. 12, no. 3, pp. 182199, 1997.

[95] R. Weissleder, "A clearer vision for in vivo imaging," Nature Biotechnology, vol. 19, no. 4, pp. 316-317, 2001.

[96] M. Ochsner, "Light scattering of human skin: a comparison between zinc(II)-phthalocyanine and photofrin II," Journal of Photochemistry and Photobiology B, vol. 32, no. 1-2, pp. 3-9, 1996.

[97] J. Eichler, J. Knof, and H. Lenz, "Measurements on the depth of penetration of light $(0.35-1.0 \mu \mathrm{m})$ in tissue," Radiation and Environmental Biophysics, vol. 14, no. 3, pp. 239-242, 1977.

[98] H. Jelínková, J. Pašta, J. Šulc, M. Němec, and P. Koranda, "Anterior eye tissue transmission for the radiation with the wavelength from eye safe region," Laser Physics Letters, vol. 2, no. 12, pp. 603-607, 2005.

[99] B. C. Wilson, W. P. Jeeves, D. M. Lowe, and G. Adam, "Light propagation in animal tissues in the wavelength range 375825 nanometers," Progress in Clinical and Biological Research, vol. 170, pp. 115-132, 1984.

[100] U. Schmidt-Erfurth and T. Hasan, "Mechanisms of action of photodynamic therapy with verteporfin for the treatment of age-related macular degeneration," Survey of Ophthalmology, vol. 45, no. 3, pp. 195-214, 2000.

[101] X.-Y. He, R. A. Sikes, S. Thomsen, L. W. K. Chung, and S. L. Jacques, "Photodynamic therapy with photofrin II induces programmed cell death in carcinoma cell lines," Photochemistry and Photobiology, vol. 59, no. 4, pp. 468-473, 1994.

[102] S. J. Bakri and P. K. Kaiser, "Verteporfin ocular photodynamic therapy," Expert Opinion on Pharmacotherapy, vol. 5, no. 1, pp. 195-203, 2004.

[103] M. Ochsner, "Photodynamic therapy: the clinical perspective. Review on applications for control of diverse tumorous and non-tumorous diseases," Drug Research, vol. 47, no. 11, pp. 1185-1194, 1997.

[104] M. Balaz, H. A. Collins, E. Dahlstedt, and H. L. Anderson, "Synthesis of hydrophilic conjugated porphyrin dimers for one-photon and two-photon photodynamic therapy at NIR wavelengths," Organic and Biomolecular Chemistry, vol. 7, no. 5, pp. 874-888, 2009.
[105] C. J. Gomer, "Preclinical examination of first and second generation photosensitizers used in photodynamic therapy," Photochemistry and Photobiology, vol. 54, no. 6, pp. 10931107, 1991.

[106] M. Krieg and R. W. Redmond, "Photophysical properties of 3,3'-dialkylthiacarbocyanine dyes in homogeneous solution," Photochemistry and Photobiology, vol. 57, no. 3, pp. 472-479, 1993.

[107] R. W. Redmond, M. B. Srichai, J. M. Bilitz, D. D. Schlomer, and M. Krieg, "Merocyanine dyes: effect of structural modifications on photophysical properties and biological activity," Photochemistry and Photobiology, vol. 60, no. 4, pp. 348-355, 1994.

[108] A. Harriman, L. C. T. Shoute, and P. Neta, "Radiation chemistry of cyanine dyes: oxidation and reduction of merocyanine 540," Journal of Physical Chemistry, vol. 95, no. 6, pp. 2415-2420, 1991.

[109] M. Krieg, J. M. Bilitz, M. B. Srichai, and R. W. Redmond, "Effects of structural modifications on the photosensitizing properties of dialkylcarbocyanine dyes in homogeneous and heterogeneous solutions," Biochimica et Biophysica Acta, vol. 1199, no. 2, pp. 149-156, 1994.

[110] W. H. H. Gunther, R. Searle, and F. Sieber, "Structure-activity relationships in the antiviral and antileukemic photoproperties of merocyanine dyes," Seminars in Hematology, vol. 29, no. 2, pp. 88-94, 1992.

[111] M. A. Salvador, L. V. Reis, P. Almeida, and P. F. Santos, "Delocalized cationic azo dyes containing a thiazole moiety," Tetrahedron, vol. 64, no. 2, pp. 299-303, 2008.

[112] P. F. Santos, L. V. Reis, P. Almeida, J. P. Serrano, A. S. Oliveira, and L. F. Vieira Ferreira, "Efficiency of singlet oxygen generation of aminosquarylium cyanines," Journal of Photochemistry and Photobiology A, vol. 163, no. 1-2, pp. 267269, 2004.

[113] L. V. Reis, J. P. Serrano, P. Almeida, and P. F. Santos, "The synthesis and characterization of novel, aza-substituted squarylium cyanine dyes," Dyes and Pigments, vol. 81, no. 3, pp. 197-202, 2009.

[114] N. Johnsson and K. Johnsson, "Chemical tools for biomolecular imaging," ACS Chemical Biology, vol. 2, no. 1, pp. 31-38, 2007.

[115] R. Weissleder, "Molecular imaging in cancer," Science, vol. 312, no. 5777, pp. 1168-1171, 2006

[116] J. Zhang, R. E. Campbell, A. Y. Ting, and R. Y. Tsien, "Creating new fluorescent probes for cell biology," Nature Reviews Molecular Cell Biology, vol. 3, no. 12, pp. 906-918, 2002.

[117] J. F. Callan, A. P. de Silva, and D. C. Magri, "Luminescent sensors and switches in the early 21st century," Tetrahedron, vol. 61, no. 36, pp. 8551-8588, 2005.

[118] A. P. de Silva, G. D. McClean, and T. S. Moody, in Encyclopedia of Supramolecular Chemistry, Marcel Dekker, New York, NY, USA, 2004.

[119] A. P. de Silva, H. Q. N. Gunaratne, T. Gunnlaugsson, et al., "Signaling recognition events with fluorescent sensors and switches," Chemical Reviews, vol. 97, no. 5, pp. 1515-1566, 1997.

[120] J. R. Lakowicz, "Radiative decay engineering: biophysical and biomedical applications," Analytical Biochemistry, vol. 298, no. 1, pp. 1-24, 2001.

[121] F. Pina, M. A. Bernardo, and E. García-España, "Fluorescent chemosensors containing polyamine receptors," European Journal of Inorganic Chemistry, vol. 2000, no. 10, pp. 21432157, 2000 . 
[122] J. P. Geue, N. J. Head, A. D. Ward, and S. F. Lincoln, "Complexation of alkali metal and alkaline earth ions by anthracene based fluorophores with one and two appended monoaza coronand receptors," Journal of the Chemical Society. Dalton Transactions, no. 4, pp. 521-526, 2003.

[123] G. Xue, J. S. Bradshaw, N. K. Dalley, et al., "The synthesis of azacrown ethers with quinoline-based sidearms as potential zinc(II) fluorophores," Tetrahedron, vol. 58, no. 24, pp. 48094815, 2002.

[124] S. K. Kim, J. H. Lee, and J. Yoon, "Fluorescent PET chemosensor for cadmium Ions in 100\% aqueous solution," Bulletin of the Korean Chemical Society, vol. 24, no. 7, pp. 1032-1034, 2003.

[125] G. Klein, D. Kaufmann, S. Schürch, and J.-L. Reymond, "A fluorescent metal sensor based on macrocyclic chelation," Chemical Communications, no. 6, pp. 561-562, 2001.

[126] M. Beltramello, M. Gatos, F. Mancin, P. Tecilla, and U. Tonellato, "A new selective fluorescence chemosensor for $\mathrm{Cu}(\mathrm{II})$ in water," Tetrahedron Letters, vol. 42, no. 52, pp. 9143-9146, 2001.

[127] M. Sauer, "Single-molecule-sensitive fluorescent sensors based on photoinduced intramolecular charge transfer," Angewandte Chemie International Edition, vol. 42, no. 16, pp. 1790-1793, 2003.

[128] G. F. Kirkbright, in Indicators, Pergamon, Oxford, UK, 1972.

[129] J. V. Ros-Lis, R. Martínez-Mánez, K. Rurack, F. Salcenón, J. Soto, and M. Spieles, "Highly selective chromogenic signaling of $\mathrm{Hg}^{2+}$ in aqueous media at nanomolar levels employing a squaraine-based reporter," Inorganic Chemistry, vol. 43, no. 17 , pp. 5183-5185, 2004

[130] J.-H. Huang, W.-H. Wen, Y.-Y. Sun, P.-T. Chou, and J.M. Fang, "Two-stage sensing property via a conjugated donor-acceptor-donor constitution: application to the visual detection of mercuric ion," Journal of Organic Chemistry, vol. 70, no. 15, pp. 5827-5832, 2005.

[131] X. Fei and Y. Gu, "Progress in modifications and applications of fluorescent dye probe," Progress in Natural Science, vol. 19, no. 1, pp. 1-7, 2009.

[132] R. M. El-Shishtawy, C. R. Santos, I. Gonçalves, H. Marcelino, and P. Almeida, "New amino and acetamido monomethine cyanine dyes for the detection of DNA in agarose gels," Bioorganic and Medicinal Chemistry, vol. 15, no. 16, pp. 5537-5542, 2007.

[133] R. Haughland, Handbook of Fluorescent Probes and Research Chemicals, Molecular Probes, Eugene, Ore, USA, 9th edition, 2002.

[134] C.-Q. Zhu, S.-J. Zhuo, H. Zheng, et al., "Fluorescence enhancement method for the determination of nucleic acids using cationic cyanine as a fluorescence probe," Analyst, vol. 129, no. 3, pp. 254-258, 2004.

[135] T. Deligeorgiev, A. Vasilev, and K.-H. Drexhage, "Synthesis of novel cyanine dyes containing carbamoylethyl componentnoncovalent labels for nucleic acids detection," Dyes and Pigments, vol. 74, no. 2, pp. 320-328, 2007.

[136] K. D. Volkova, V. B. Kovalska, A. O. Balanda, et al., "Cyanine dye-protein interactions: looking for fluorescent probes for amyloid structures," Journal of Biochemical and Biophysical Methods, vol. 70, no. 5, pp. 727-733, 2007.

[137] T. Deligeorgiev, N. Gadjev, A. Vasilev, K.-H. Drexhage, and S. M. Yarmoluk, "Synthesis of novel monomeric and homodimeric cyanine dyes with thioacetyl substituents for nucleic acid detection," Dyes and Pigments, vol. 72, no. 1, pp. 28-32, 2007.
[138] B. A. Armitage, "Cyanine dye-nucleic acid interactions," in Heterocyclic Polymethine Dyes, Topics in Heterocyclic Chemistry, pp. 11-29, Springer, Berlin, Germany, 2008.

[139] I. Timtcheva, V. Maximova, T. Deligeorgiev, D. Zaneva, and I. Ivanov, "New asymmetric monomethine cyanine dyes for nucleic-acid labelling: absorption and fluorescence spectral characteristics," Journal of Photochemistry and Photobiology A, vol. 130, no. 1, pp. 7-11, 2000.

[140] I. I. Timcheva, V. A. Maximova, T. G. Deligeorgiev, N. I. Gadjev, R. W. Sabnis, and I. G. Ivanov, "Fluorescence spectral characteristics of novel asymmetric monomethine cyanine dyes in nucleic acid solutions," FEBS Letters, vol. 405, no. 2, pp. 141-144, 1997.

[141] H. S. Rye, S. Yue, D. E. Wemmer, et al., "Stable fluorescent complexes of double-stranded DNA with bis-intercalating asymmetric cyanine dyes: properties and applications," Nucleic Acids Research, vol. 20, no. 11, pp. 2803-2812, 1992.

[142] C. Carlsson, A. Larsson, M. Jonsson, B. Albinsson, and B. Nordén, "Optical and photophysical properties of the oxazole yellow DNA probes YO and YOYO," Journal of Physical Chemistry, vol. 98, no. 40, pp. 10313-10321, 1994.

[143] M. R. Mazières, C. Duprat, J. G. Wolf, and A. D. Roshal, "pH dependent spectral properties and electronic structure of benzothiazol containing cyanine dyes," Dyes and Pigments, vol. 80, no. 3, pp. 355-360, 2009.

[144] C. Encinas, S. Miltsov, E. Otazo, L. Rivera, M. Puyol, and J. Alonso, "Synthesis and spectroscopic characterisation of heptamethincyanine NIR dyes for their use in optochemical sensors," Dyes and Pigments, vol. 71, no. 1, pp. 28-36, 2006.

[145] M. Puyol, C. Encinas, L. Rivera, S. Miltsov, and J. Alonso, "Synthesis of new ketocyanine dyes for the development of optical sensors. Optical characterisation and solvatochromic behaviour," Sensors and Actuators B, vol. 115, no. 1, pp. 287296, 2006.

[146] Y. Xu, Y. Liu, and X. Qian, "Novel cyanine dyes as fluorescent $\mathrm{pH}$ sensors: PET, ICT mechanism or resonance effect?" Journal of Photochemistry and Photobiology A, vol. 190, no. 1, pp. 1-8, 2007.

[147] R. M. El-Shishtawy and P. Almeida, "A new Vilsmeier-type reaction for one-pot synthesis of $\mathrm{pH}$ sensitive fluorescent cyanine dyes," Tetrahedron, vol. 62, no. 33, pp. 7793-7798, 2006. 


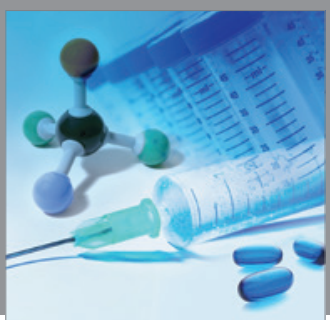

International Journal of

Medicinal Chemistry



Carbohydrate Chemistry



The Scientific World Journal
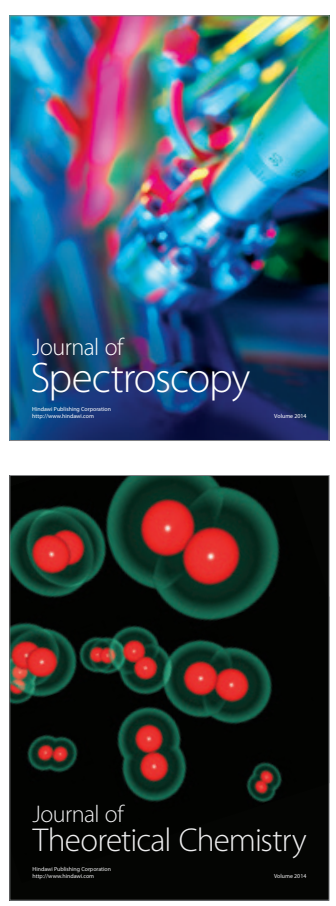
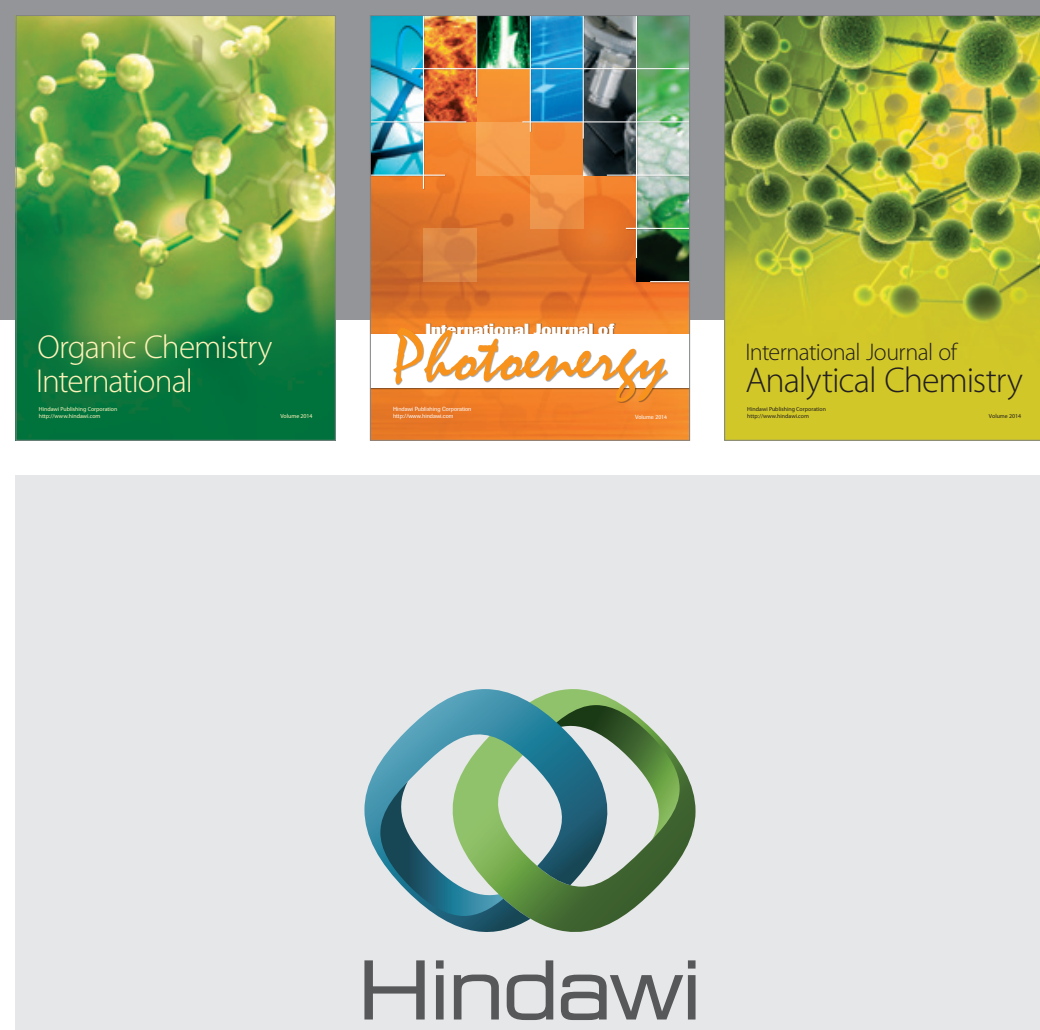

Submit your manuscripts at

http://www.hindawi.com
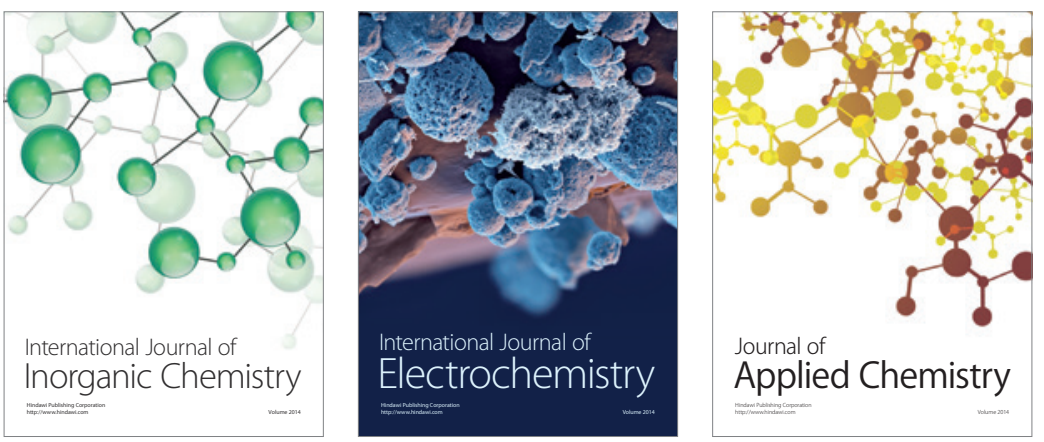

Journal of

Applied Chemistry
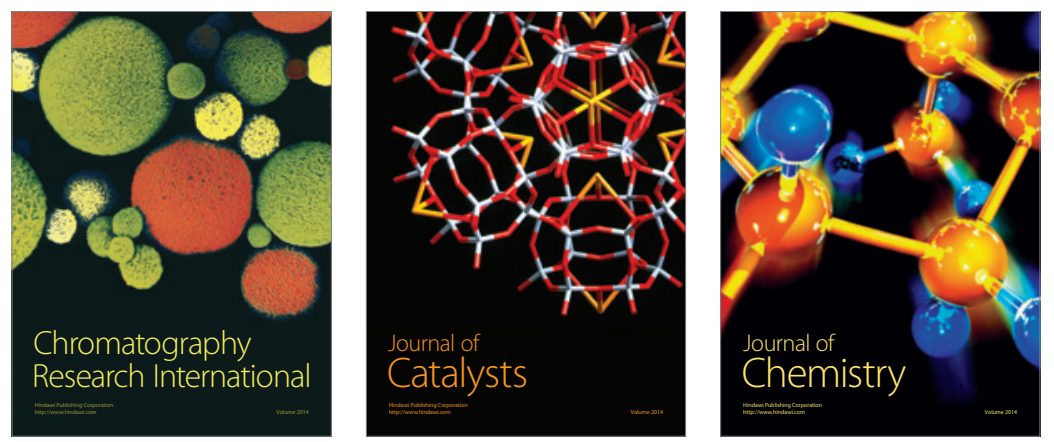
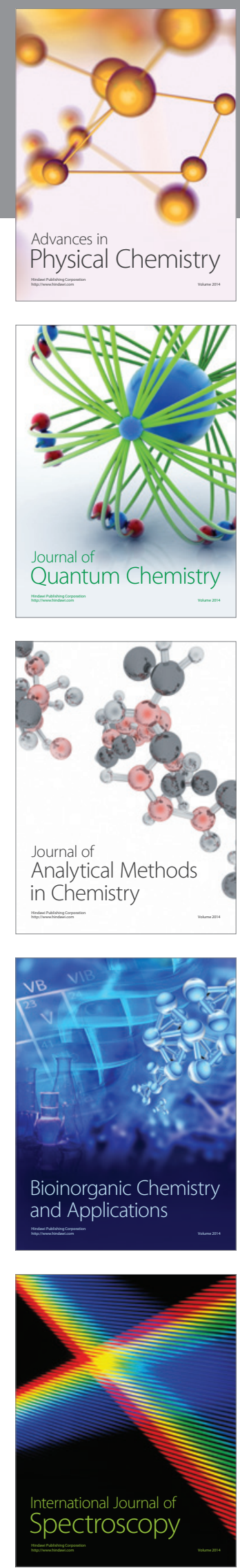